\title{
El soporte logístico de la especialización económica de Andalucía durante el primer tercio del siglo XX
}

\author{
Andrés Sánchez Picón \\ Universidad de Almería \\ aspicon@ual.es \\ Domingo Cuéllar \\ cuellar.domingo@gmail.com
}

El soporte logístico de la especialización económica de Andalucía durante el primer tercio del siglo XX (Resumen)

Los cambios en el transporte de mercancías durante el siglo XIX conllevaron unas mejoras significativas en las prestaciones de los diferentes modos de transporte. Sin embargo, estas evoluciones no solucionaban el problema completamente y fue necesario integrar las diferentes cadenas de transporte en una sola, que diera continuidad con la mayor eficiencia posible al flujo de mercancías para reducir los costes de transporte y los tiempos de viaje, y aumentar los volúmenes de carga y el valor de las mercancías en los mercados de destino.

La economía andaluza entró en el primer tercio del siglo XX en este proceso, a través de una nueva etapa de especialización económica basada en la explotación de sus recursos naturales. Se desarrolló entonces un potente sector agroalimentario y su industria asociada (aceite, azúcar, vino, etc.), y se alcanzó también el máximo apogeo en la demanda de materias primas minerales.

Lograr esa especialización económica requirió una profunda modernización logística, una relativamente rápida modernización de las redes de tráfico y un incremento de los intercambios entre los diferentes modos de transporte.

Palabras clave: Historia Económica, Segunda Revolución Tecnológica, Transporte

Logistical support of economic specialization of Andalusia during the first third of the 20th century (Abstract)

Changes in freight during the 19th century brought significant improvements in the performance of the different modes of transport. However, these changes did not solve the problem completely and it was 
necessary to integrate the different transport chains in one, to give continuity with the most efficient flow of goods to reduce transport costs and travel times, and increase cargo volume and value of goods in the target markets.

The regional economy entered the first third of the 20th century in this process through a new stage of economic specialization based on the exploitation of its natural resources. It then develops a powerful agri-food sector and its associated industries (oil, sugar, wine, etc.), and also reached the peak in demand for mineral raw materials.

Reaching that economic specialization required a profound logistics modernization, a relatively rapid modernization of trafficking networks and increased exchanges between different modes of transport.

Key words: Economic History, Second Technological Revolution, Transport

El transporte de mercancías a media y larga distancia conlleva casi siempre el uso de diversos modos combinados entre sí1. Esto, que resulta ahora evidente y se asocia al concepto de intermodalidad ${ }^{2}$, no resulta tan fácil de aplicar a la combinación de medios de transportes que se dio, sobre todo, a partir de las innovaciones derivadas de la Segunda Revolución Tecnológica (SRT), entre finales del siglo XIX y primer tercio del siglo XX.

Estas transformaciones conllevaron una revolución logística que arrancó en la SRT y se ha culminado en las últimas décadas del siglo XX, favorecida por las mejoras técnicas, la innovación organizativa y el crecimiento de los mercados, con el consiguiente aumento del trasiego de mercancías entre Asia, Estados Unidos y Europa ${ }^{3}$.

Sin embargo, hasta la irrupción de las primeras etapas de la coordinación y complementariedad de los transportes, estos se habían caracterizado por la sucesión de hegemonías modales basadas en las prestaciones tecnológicas de cada uno, dependiendo de las características de cada país. En Europa Occidental, la relevancia del transporte marítimo en la época moderna fue sucedida en el siglo XVIII por una plenitud de la navegación en canales e inmediatamente después por el siglo ferroviario, al que en la centuria siguiente le salieron nuevos competidores, como la automoción o la aviación, produciéndose, además, el grado mayor de desarrollo técnico y organizativo en cada uno de estos modos de transporte. Es en ese momento cuando surge la necesidad de integrar las diferentes cadenas de transporte en una sola que diera continuidad con la mayor eficiencia posible al flujo de mercancías para reducir los costes de transporte, los tiempos de viaje y aumentar los volúmenes de carga, consiguiendo de este modo elevar el valor de las mercancías en los mercados de destino.

La innovación tecnológica ha sido la base del progreso de la sociedad contemporánea y ha constituido "una de las fuerzas más poderosas de la historia"". El transporte, como es lógico,

\footnotetext{
${ }^{1}$ Este trabajo forma parte del proyecto de investigación del Ministerio de Economía y Competitividad "Marco institucional y externalidades en la minería ibérica (siglos XVIII-XXI)", HAR2014-56428-C3-2-P. Una primera versión del mismo fue presentada en las Primeras Jornadas Internacionales "La industria en los inicios de la Segunda Revolución Tecnológica" de la Revista de Historia Industrial, celebradas en Antequera los días 2 y 3 de diciembre de 2010.

${ }^{2}$ La definición actual de intermodalidad se aproxima a la idea de la existencia de un sistema de transporte integrado por distintos modos, que constituye una cadena de origen a destino, caracterizado por la presencia de un recipiente único de transporte (container tipo TEU) que evita rupturas de carga. Comisión de Transportes de CICCP, 2005.

${ }^{3}$ Vahrenkamp, 2012.

${ }^{4}$ Mokyr, 1993, p. 18. Con una mayor profundización en el análisis y donde se vuelve a defender el liderazgo del cambio tecnológico como verdadero motor de la Revolución Industrial, Mokyr, 2008.
} 
también ha vivido una incesante espiral evolutiva que es visible tanto en las técnicas de construcción de infraestructuras como en el desarrollo de mecanismos motores que multiplican su eficiencia y capacidad de transporte sobre los primeros artilugios del vapor. Sin embargo, junto a este progreso mecánico también hay que contabilizar una profunda transformación de las tecnologías de gestión, tal y como mostró Chandler al referirse precisamente a dos ejemplos de empresas de transporte y comunicaciones en Estados Unidos -ferrocarriles y telégrafos- como origen del capitalismo gerencial y de la moderna empresa ${ }^{5}$.

Es, pues, indudable la relación de identidad entre el transporte y la tecnología, entendida ésta en su más amplia acepción. Ya que tecnología es también el modo de organizar los servicios y preparar los procesos de intercambio de viajeros o mercancías con otros medios de transporte, conocidos como transbordos o ruptura de carga. Thomson hacía referencia a tres opciones de elección en el transporte que estaban relacionados con la eficiencia tecnológica: por un lado, la modalidad, por otro lado, el transbordo entre diferentes modos, y, por último, el desarrollo de mejoras en modos y transbordos ${ }^{6}$.

Así pues, además de la mejora de las infraestructuras y los vehículos, el transporte precisa de un plus que viene dado por la eficiencia y que empezó a ponerse de manifiesto ya en los primeros momentos de la Revolución Industrial, que posteriormente se desarrolló durante la SRT y que hoy en día es marca de referencia bajo la denominación de servicios logísticos ${ }^{7}$. La construcción de la logística del transporte se empieza a fraguar en aquel momento, cuando los gestores de los diferentes modos de transporte encuentran menos obstáculos en la relación de intercambio de tráficos con otros medios. En cierto modo, es también el resultado de una elección y de la búsqueda de una ventaja competitiva en determinados tráficos.

La construcción de las relaciones intermodales, en todo caso, fue lenta e irregular. Para el caso francés, se ha explicado la existencia en un primer momento, a mediados del siglo XIX, de una etapa de complementariedad y alianzas entre el emergente ferrocarril, el cabotaje y los transportes tradicionales. Esta situación de equilibrio se vio rota a finales del siglo XIX por la feroz competitividad que se establecía entre unos medios de transporte cada vez más eficientes que luchaban por la hegemonía. Tras la Primera Guerra Mundial se inició una situación de consenso, propiciado por las tareas de coordinación por parte del Estado, de los servicios de transporte ${ }^{8}$. Resulta también identificable este proceso en España, aunque tal vez con alguna década de retraso, ya que los intentos más profundos en la coordinación de los transportes no se iniciarían hasta los cortos años de la Segunda República, después de una década de 1920 con un intenso debate sobre la competencia y la hegemonía de los diferentes modos de transporte 9 .

La escasez de trabajos concretos que analicen, bien a escala nacional o regional, los flujos de transporte de mercancías en los comienzos del siglo XX en España, nos hizo en un trabajo anterior interesarnos ${ }^{10}$, a partir del caso andaluz, por la configuración del sistema de

\footnotetext{
${ }^{5}$ Chandler, 2008, Segunda Parte, p. 129-301.

${ }^{6}$ Thomson, 1976, p. 273-274.

${ }^{7}$ El estudio del caso estadounidense, en Fair y Williams, 1975. Más recientemente, desde la perspectiva de la globalización, Vahrenkamp, 2012.

${ }^{8}$ Marnot, 2006.

${ }^{9}$ Hasta ahora contamos con escasa bibliografía sobre este proceso. Unas primeras aproximaciones en Hernández Marco, 2002, y Martínez Vara y De los Cobos, 2006.

${ }^{10}$ Sánchez Picón y Cuéllar, $2010 b$.
} 
transportes de la región económica de Andalucía ${ }^{11}$. En el mismo, analizábamos los procesos de inversión en la construcción de las infraestructuras, la relación de la actividad productiva con el desarrollo de esas redes de transporte $\mathrm{y}$, finalmente, la evolución del transporte de viajeros en los diferentes modos, origen en parte de la intensa disputa entre los intereses ferroviarios y del transporte mecanizado por carretera en la España de las décadas de 1920 y 1930.

La economía andaluza entraría desde el último tercio del siglo XIX en una nueva etapa, una vez superado ese débil arranque industrializador que en el segundo tercio del siglo XIX tuviera por protagonista fundamental el foco malagueño. Tras el aborto de este débil fogonazo ${ }^{12}$, la economía andaluza se adentraría por una nueva senda de especialización económica basada en la explotación de sus recursos naturales. Exponente de este nuevo camino sería el desarrollo de un potente sector agroalimentario basado en el crecimiento de determinadas producciones agrícolas y la expansión de una industria asociada a la transformación de estas materias (aceite, azúcar, vino, etc.). Por otro lado, la demanda de materias primas minerales por parte de las manufacturas europeas durante la segunda industrialización, colocó a la extracción minera en el apogeo de su actividad. Tanto las producciones agrícolas como las mineras suponían un avance en la senda de la especialización económica que requería una profunda transformación en ese dispositivo logístico que permitía el trasiego de materiales, suministros y mercancías desde los lugares de producción hasta los canales de transporte que los conducirían a sus mercados ${ }^{13}$. Además, la especialización suponía el incremento de las entradas de determinados suministros (carbones o cereales) importados desde lugares cada vez más lejanos tanto del mercado nacional como del internacional. Sin una relativamente rápida modernización de las redes de tráfico y de los intercambios entre los diferentes modos de transporte, no hubiera sido posible avanzar en el proceso de modernización económica sostenido por ese aumento de la integración económica y de la especialización productiva.

En el texto que presentamos ahora, nos centraremos en el estudio del transporte de mercancías. Para ello señalaremos primeramente cómo se configuraron las principales infraestructuras de transporte en Andalucía a lo largo del periodo estudiado. A continuación, analizaremos las formas y características del transporte de las principales mercancías en cada uno de los sectores productivos. Igualmente, dedicaremos un apartado a señalar aquellas coordinaciones puntuales que se dieron en los transportes intermodales en el periodo, especialmente el ferromarítimo. Finalizaremos con unas conclusiones sobre lo estudiado.

\section{La configuración de redes de transporte}

En 1880, la modernización de los espacios de transporte andaluces estaba todavía en fase de montaje (figura 1). Como es sabido, el desarrollo de la explotación ferroviaria trajo consigo la integración de un mercado nacional, hasta ese momento fragmentado a causa de las grandes dificultades del transporte terrestre interior. Con la consumación de las conexiones interiorperiferia, especialmente a través del ferrocarril, pero también de modo paralelo con las carreteras de macadán, se redujeron enormemente los costes de transporte y quedó garantizado el suministro, cuestiones ambas fundamentales en la integración de un mercado nacional o regional.

\footnotetext{
${ }^{11}$ Sobre este concepto y su análisis en perspectiva histórica, Lizárraga, 2003.

12 Nadal, 1984.

${ }^{13}$ Parejo, 2008.
} 


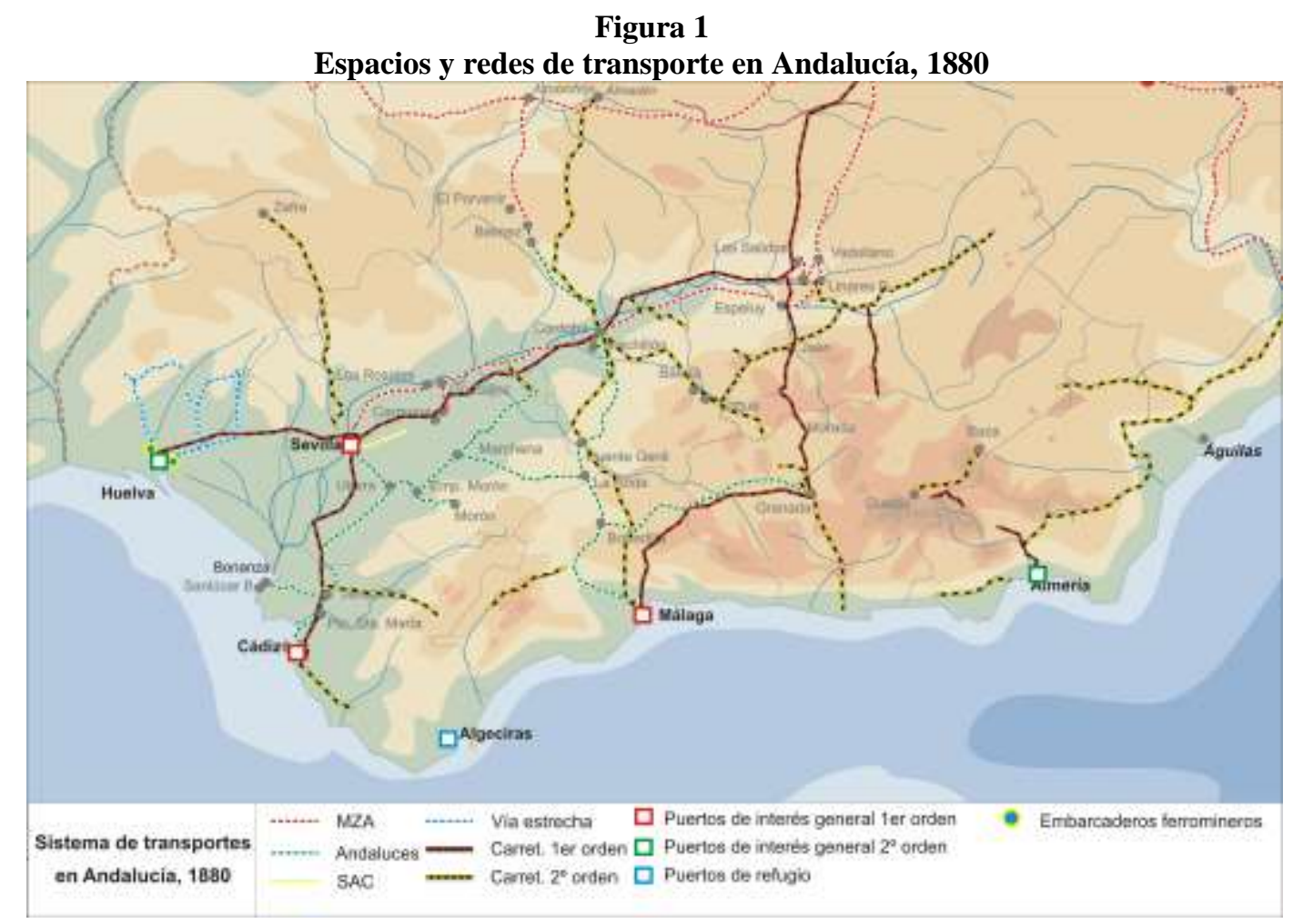

Fuente: elaboración propia.

Al iniciarse ese último cuarto del siglo XIX, el crecimiento de la producción andaluza, del consumo interior y de la actividad comercial era un hecho. De forma similar al caso español, el volumen de mercancías transportadas por los ferrocarriles y puertos andaluces se había duplicado con creces entre 1870 y 1880 , pasando de las 600 mil toneladas de 1870 por ferrocarril y las 800 mil en los puertos a los 1,2 y 1,9 millones, respectivamente. Igualmente el transporte de viajeros por ferrocarril había mostrado un crecimiento más moderado, pero significativo, al pasar de 1,8 millones de viajeros en 1870 a 2,2 millones una década después ${ }^{14}$.

Sin embargo, como hemos apuntado ya, el sistema de transportes andaluz estaba todavía en fase de realización, como demuestra el hecho de que la red ferroviaria estuviera todavía por debajo del $50 \%$ de la red que se consolidó en el siglo XX $(1.500 \mathrm{~km}$ en 1880 sobre $3.500 \mathrm{~km}$ en 1935) y la de carreteras con sólo un 20\% de la que estaría operativa en 1935 (2.700 de carreteras de macadán en 1880 , sobre los 15.000 construidos en 1935) ${ }^{15}$. En realidad, los primeros esfuerzos se hicieron sobre los ejes de comunicación de las principales ciudades a lo largo del valle del Guadalquivir y los accesos a las ciudades y puertos de Málaga y Cádiz; sólo los primeros ferrocarriles mineros de Huelva y la construcción de la carretera de Almería a Puerto Lumbreras -también con claros intereses mineros-, a un extremo y otro de la geografía andaluza, alteraban esta hegemonía bética.

En el caso de los ferrocarriles, numerosas estaciones y muelles estaban todavía construyéndose, no olvidemos que las grandes estaciones ferroviarias andaluzas como Sevilla-Plaza de Armas, Jerez de la Frontera, Linares o Cádiz no tuvieron sus edificios definitivos -tanto de viajeros como de servicios- hasta los últimos años del siglo XIX o

\footnotetext{
${ }^{14}$ Cálculo realizado a partir de los datos aportados por Ruiz, 2004, para el caso de los puertos, y Cuéllar, Jiménez Vega y García Raya, 2008, para los ferrocarriles.

${ }^{15}$ Datos en Sánchez Picón y Cuéllar, 2010 b.
} 
incluso más tarde. Hasta ese momento, edificios provisionales y muelles también provisionales, eran los marcos de intercambio de mercancías entre los ferrocarriles y las carreteras. Estas últimas drenaban de manera claramente insuficiente el tráfico derivado del crecimiento de la circulación ferroviaria, ya que las construcciones se volcaron inicialmente en la realización de las carreteras de primer y segundo orden, que corrían paralelas en la mayoría de los casos a los ferrocarriles, por lo que una buena parte de los tráficos locales y de corto recorrido, que constituían la base económica del tejido productivo, se seguían haciendo por antiguos caminos de ruedas o herradura.

Por su parte, en los puertos ya se habían constituido algunas Juntas de Obras de Puertos Sevilla (1870), Huelva y Málaga (1874) y Almería (1878)-, que eran organismos públicos que recibían financiación del Estado pero que también disponían de cierta autonomía para gestionar y proveer recursos propios. Ya en el siglo XX se completaría el panorama de las juntas portuarias andaluzas con Cádiz, en 1901, y Algeciras, en 1907. Estas juntas tendrían unos claros fines comerciales y por ello pusieron notable empeño en la mejora de los servicios y de la conexión con otros medios de transporte. Aquí confluían los discursos de las memorias de las juntas portuarias y de las asambleas de accionistas ferroviarias. En este sentido, la Compañía de los Ferrocarriles Andaluces (en adelante, Andaluces) realizó sucesivas declaraciones de demanda de mejoras en los puertos de Cádiz, Málaga y Sevilla, cuestión que consideraba fundamental para poder conseguir incrementar sus tráficos hacia y desde estos puntos. Por eso seguía con fervor la realización de obras en los muelles de Puntales en Cádiz, en la batería San Rafael en Málaga o a orillas del Guadalquivir en Sevilla, aunque también se lamentaba las paralizaciones y retrasos que había en estos puntos ${ }^{16}$.

Sin embargo, la historia de la obra pública está plagada de pleitos y paralizaciones y, en este caso, los intereses encontrados entre las juntas de obras de puertos, las compañías ferroviarias y los municipios fue causa de algunos conflictos jurisdiccionales que demoraban largamente la finalización de la obra. Así ocurriría a finales de la década de 1870 con el muelle de Bonanza en el que la compañía Andaluces y el ayuntamiento de Sanlúcar de Barrameda no se pusieron de acuerdo acerca de los terrenos de uso para el ramal de cuatro kilómetros hasta Bonanza, donde se ubicaba el embarcadero que daría salida a una parte de la producción bodeguera de la zona ${ }^{17}$. Mucho más prolongado sería el contencioso entre la Junta de Obras del Puerto de Almería y los directivos de la Compañía de los Caminos de Hierro del Sur de España (Sur) acerca de los límites de titularidad de cada uno de ellos en la construcción del ramal ferroviario hasta el puerto, conflicto que se inició con la apertura de la línea en 1895 y que no se cerraría hasta el acuerdo de 1925, funcionando en ese periodo un trazado provisional $^{18}$.

También hay que recoger que otras conexiones portuarias no eran explotadas en todo su potencial, como ocurrió durante mucho tiempo con la conexión ferroportuaria de Algeciras. Las razones eran políticas y residían en el conflicto internacional entre Gran Bretaña y España sobre la posesión de Gibraltar. Esto hacía que la conexión no fuera vista con buenos ojos e inclusive que se postergara la construcción de la línea ferroviaria sobre esta zona por ciertos conflictos estratégicos de la defensa nacional. Así, la línea litoral Cádiz, Algeciras, Málaga derivó en una conexión interior Jerez a Algeciras, impulsada por capitales británicos, que ante la falta de concreción llevó a la definitiva construcción de Bobadilla a Algeciras, también con

\footnotetext{
${ }^{16}$ Ver ejemplos en Memorias de Andaluces, 1878, p. 19, 1881, p. 15 y 19, 1884, pp. 6 y 25, 1885, p. 15.

${ }^{17}$ Memorias de Andaluces, 1877-1881.

${ }^{18}$ Sánchez Picón y Cuéllar, 2010a, p. 169-171.
} 
apoyo financiero británico, pero que cuyo trazado respondía más a los intereses locales del ayuntamiento rondeño ${ }^{19}$.

Sorprende ahora conocer que el puerto algecireño no tuviera conexión con carretera del Estado hasta 1880 y que la vía férrea no llegara hasta 1892, y todavía de modo precario. Además, aunque las memorias de obras públicas recogían su importancia como "puerto de entrada a África" 20 , su proyecto de construcción sufriría continuas demoras y sólo se activaría hasta la constitución de la Junta de Obras del Puerto en 1907. La vocación internacional y transcontinental que se le atribuyó a esta conexión durante la segunda mitad del siglo XX estuvo, por lo tanto, durante mucho tiempo limitada y dio como resultado unos tráficos muy modestos $^{21}$.

La cuestión de la lógica de los trazados ferroviarios y sus dinámicas cambiantes en el largo plazo ya tuvimos ocasión plantearlo al analizar el caso de la línea de Linares a Almería $^{22}$ y constatamos entonces que las realidades y demandas de un siglo atrás muchas veces tienen poco que ver con las necesidades actuales. Los cambios económicos y demográficos de Andalucía a lo largo del siglo XX han diseñado un espacio económico y social que está bastante alejado del que se gestionaba a finales del siglo XIX. Por eso sus trazados ferroviarios muestran rasgos de ineficacia, como por ejemplo la carencia de una línea costera ferroviaria que articulara la zona más dinámica de la región, o la baja actividad de las líneas que recorren zonas de escasas población en sentido interior-litoral. De hecho muchas de estas líneas no estaban aún construidas a la conclusión del primer impulso ferroviario andaluz, sino que se iban a construir a partir de 1880, bajo la presión de la demanda de los intereses mineros que buscaban caminos directos hasta el mar.

Los límites al diseño de esos trazados venían impuestos por la disponibilidad de técnicas de construcción capaces de salvar fuertes pendientes y de construir grandes viaductos y túneles. Las líneas de vía ancha de Zafra a Huelva (1886-1889), de Baza a Lorca y Águilas (18901895) y de Linares a Almería (1895-1899) muestra esa cara minera y montañosa de los ferrocarriles andaluces. También habría que incluir en este grupo las líneas de Belmez a Córdoba (1870-1873) y de Córdoba a Málaga (1863-1865), sobre todo si se tiene en cuenta que el origen de la concesión estuvo en el interés de empresarios malagueños para acceder a los cotos hulleros del Alto Guadiato para el suministro a las industrias metalúrgicas. En todos los casos, estas líneas sacrificaron el interés comercial y económico en los trazados por el camino directo. Así, en el caso malagueño Antequera quedó fuera del eje principal, en la línea de Almería fueron sacrificados sobre todo Úbeda y el Alto Andarax, y en la línea de Águilas se postergó el interés del paso por la comarca de los Vélez.

Pero una buena parte de la red ferroviaria andaluza tendría una vocación agraria indudable, puesto que los tráficos de cereales, vinos y aceites fueron muy valorados en los estudios previos que realizaron muchas de estas compañías. El incremento de la producción agraria, lento pero constante, el aumento de la población y por lo tanto del mercado, y las ventajas del ferrocarril para este transporte hizo pensar que la gran producción agraria andaluza sería una

\footnotetext{
${ }^{19}$ Cuéllar, 2008b, p. 198-202.

${ }^{20}$ Memoria de Obras Públicas, 1881.

${ }^{21}$ Esta situación contrasta con el momento actual, con su liderazgo nacional con unos 20 millones de toneladas movidos anualmente, por encima de Valencia y duplicando a Bilbao o Barcelona. Si bien el bagaje ferroviario sigue siendo muy pobre, con 200 mil toneladas, sólo un 1\%. Datos tomados de Memorias de Puertos del Estado, año 2005.

${ }^{22}$ Cuéllar y Sánchez Picón, 1999.
} 
garantía de tráficos productivos. Las expectativas se vieron pronto decepcionadas, y sólo en aquellos puntos en los que el elemento urbano reforzó el consumo y los tráficos se pudieron obtener resultados favorables. También algunas líneas andaluzas tuvieron un evidente diseño agrario como las que atravesaban las campiñas cordobesas y sevillanas, si bien el mejor ejemplo sería algo tardío, la línea de Puente Genil a Linares, que en realidad escondía una apuesta minera para competir con los tráficos de los plomos de Linares con la Compañía de los Ferrocarriles de Madrid a Zaragoza y Alicante (MZA). Pero los impulsores del proyecto defendían la importante actividad oleícola de las comarcas que atravesaba la línea, aunque a menudo dejaban escapar su deserción agraria, esperando que los apartaderos industriales revitalizaran los tráficos de las líneas de Andaluces:

“... las regiones que cruzan nuestras líneas van desarrollando en efecto su industria, y por tanto, la importancia de los transportes dejará de estar ligada de modo tan importante, como lo ha estado anteriormente, a la abundancia o escasez de cosechas" ${ }^{\text {23. }}$.

Además de las líneas mineras y de las líneas agrarias también se pueden localizar líneas de carácter estratégico, como el eje transversal interior Utrera-Marchena-La Roda que ponía en comunicación no sólo las dos líneas más productivas de Andaluces, Sevilla-Cádiz y CórdobaMálaga, sino que también lo hacían con los tres puertos de las referidas ciudades como manifestaban con gran solemnidad los propietarios de la compañía andaluza al poco tiempo de su construcción:

“...dueños del tráfico de los grandes centros andaluces entre el Océano y el Mediterráneo»²4.

Las estrategias de adquisición de estas líneas o ampliaciones que hizo Andaluces se debieron a tres fines básicos: ampliación de mercados y búsquedas de economías de escala (adquisición de la línea de Sevilla a Cádiz, 1878); acciones defensivas para evitar entrada indeseada de competidores (Linares a Almería, 1916-1929); y sociedades en liquidación por inviabilidad económica (Córdoba a Belmez, 1879, y Bobadilla a Algeciras, 1913). Según Tedde, Andaluces seguía así las estrategias de ampliación que habían realizado Norte (Compañía de los Caminos de Hierro del Norte de España) y MZA en el resto de España, financiándose para ello con las facilidades del mercado de capitales francés ${ }^{25}$.

Volviendo a la relación física entre carreteras, ferrocarriles y puertos, hemos de tener presente que la localización de los puertos andaluces confirma esa dualidad valle-montaña que planteábamos más atrás, ya que, de los grandes puertos, sólo Cádiz y Sevilla escapan a la influencia de la montaña. Esto significa para la consecución de la deseada intermodalidad un serio condicionante que no hay que olvidar, ya que en muchos casos esas líneas ferroviarias perpendiculares eran la única conexión terrestre que tenían los puertos, debido a que las carreteras se demoraron y que no era posible la conexión ferroviaria paralela a la costa. En realidad, sólo a lo largo del eje Sevilla-Jerez-Cádiz podemos encontrar una concurrencia de trazados paralelos (carretera-ferrocarril-navegación) desde una fecha tan temprana como 1861, cuando se culminó la línea ferroviaria.

Por eso la construcción de la intermodalidad $-\mathrm{o}$ al menos las primeras conexiones intermodales- era tan importante en buena parte de Andalucía: porque su ausencia restringía gravemente el tráfico ante la falta de una alternativa eficiente.

\footnotetext{
${ }^{23}$ Memorias de Andaluces, 1899, p. 14.

${ }^{24}$ Memorias de Andaluces, 1878, p. 17; véase también, 1885, p. 25.

${ }^{25}$ Tedde, 1980, p. 106-107.
} 


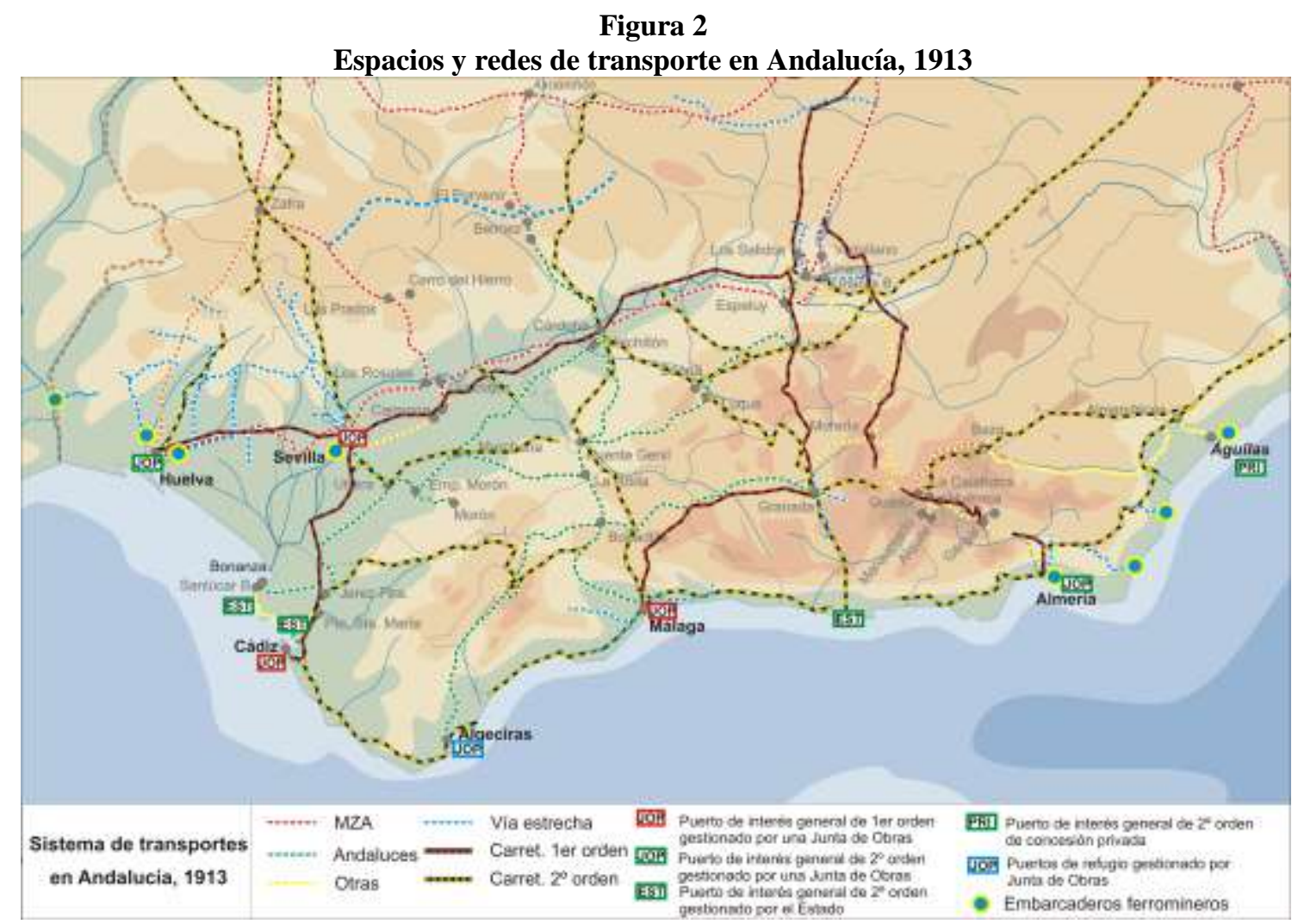

Fuente: elaboración propia.

\section{Las tipologías de los tráficos de mercancías}

\section{Los flujos mineros}

La minería (salvo que se trate de materias de muy alto valor por unidad de volumen) es un sector muy sensible a los gastos de transporte, en una mercancía sometida, además, a la característica elevada volatilidad de los mercados internacionales de materias primas minerales $^{26}$. En estas condiciones, el trasiego de minerales ha supuesto para la empresas mineras la búsqueda de un equilibrio entre el recurso al mercado, a las empresas, públicas o privadas, que ofrecían un servicio de transporte a menudo insuficiente, o su internalización, para adecuarlo al volumen de tráfico requerido, pero con el consiguiente riesgo de sobredimensionar su inmovilizado y soportar unas elevadas cargas financieras.

Los requerimientos logísticos de este tipo de transportes evolucionaron a lo largo del siglo XIX. Hasta los años 1870-1880 predominaría la tracción de sangre y no llegarían a acometerse inversiones para el acondicionamiento de los lugares de embarque. En el caso de las exportaciones de plomo, el principal producto minerometalúrgico hasta el último tercio del siglo XIX, las necesidades de transporte de suministros (combustible vegetal y mineral, sobre todo) y del movimiento de los minerales y metales (hasta las fundiciones y de éstas hasta los puntos de embarque), supusieron una movilización de hombres y bestias de carga sin precedentes, apenas contrarrestado por el progresivo predominio de la localización de las

\footnotetext{
${ }^{26}$ En un informe del Departamento de Asuntos Económicos y Sociales de las Naciones Unidas de 1976 sobre la aplicación de la moderna tecnología del transporte al desarrollo de los recursos minerales en los países en desarrollo, se afirmaba que del 55 al 75\% de los costos totales de un mineral entregado al consumidor (fundidor, fabricante o contratista) correspondía a los gastos del transporte, y rara vez ese componente era inferior al 3540\%. Departamento de Asuntos económicos y sociales de las Naciones Unidas, 1976.
} 
fundiciones en el litoral. La arriería, ofertada tanto por transportistas especializados como por campesinos que encontraban una fuente de ingresos complementaria a los meramente agrícolas en el ejercicio de esta actividad, debió crecer extraordinariamente. Los datos que aportan algunos testigos son espectaculares ${ }^{27}$. Incluso desde otros ámbitos profesionales como la pesca, la mano de obra desocupada y muchas embarcaciones menores (faluchos y barcas) encontrarían empleo en el acarreo y embarque de minerales y metales, urgentemente requeridas dada la inexistencia de infraestructuras portuarias en los playas donde se efectuaban las exportaciones, que facilitaran el atraque de los buques y las operaciones de estiba $^{28}$.

El tonelaje requerido por la minería andaluza a partir de la Segunda Revolución Tecnológica sería incomparablemente mayor que el del periodo precedente. Esta circunstancia, y el predominio del movimiento de graneles minerales sobre los semitransformados (plomo metal) del periodo anterior, obligaron a una remodelación profunda de la organización del transporte.

El apogeo minero andaluz entre 1890 y 1920 supuso, sólo refiriéndonos a las producciones hegemónicas (piritas, hierro y plomo), la movilización de unos 117 millones de toneladas de minerales y metales vendibles. Ese volumen oculta cualidades y precios muy diferentes y, en consecuencia, elasticidades muy diversas en relación al coste de transporte. Casi el $99 \%$ de este volumen estuvo compuesto por materias primas minerales como las piritas (81 millones, equivalentes al 70\%) y mena de hierro (33 millones que suponían el $28 \%$ ), frente al apenas $2 \%$ aportado por un producto semitransformado como el plomo en barras (casi 3 millones de toneladas). En 1890, en las fechas iniciales de la explotación a gran escala del hierro y las piritas, una tonelada de minerales del primero en el puerto de Almería tenía un precio FOB de unas $4,30 \mathrm{pts}^{29}$. Ese mismo año, en Huelva la tonelada de piritas valía unas $31 \mathrm{pts}$, mientras que la de plomo en Linares alcanzaba las 283 y 351 pts en Londres. Está claro que el transporte de las materias primas era inviable sin el concurso de un nuevo medio de gran capacidad, que permitiera disminuir el coste unitario de la conducción de unos graneles de tan bajo precio ${ }^{30}$. Los resultados de los transportes tanto por ferrocarril como en los puertos corroboran esta relación entre la producción minera y los flujos de transporte en ese periodo (figura 3).

Tanto las grandes como las pequeñas empresas mineras se vieron obligadas a afrontar el reto de la modernización del transporte y el abandono de la tracción animal. Las soluciones (vías terrestres o cables aéreos, anchura de vías, sistemas de tracción, etc.) variaron en función de consideraciones financieras y técnicas.

\footnotetext{
${ }^{27}$ Hacia 1835 Pedro Julián Contreras estimaba las personas dedicadas a la minería en Sierra de Gádor en unos 20.000 individuos, de los que de 12 a 14.000 estarían en las minas, unos 2.000 en las fundiciones y en el acopio de leñas, otros 2.000 encargados en la compra de minerales, y otros 2.000 a cargo de las 6.000 acémilas que conducían las menas desde las explotaciones a las fábricas y desde éstas a los puertos de embarque.

${ }^{28}$ Esta dedicación complementaria de los pescadores seguía estando vigente décadas más tarde cuando el geógrafo francés Casimir Delamarre visite la costa de Almería. Delamarre, 1866.

${ }^{29}$ Como otros casos de incoterm, la evolución de su significado ha sido progresiva. FOB se aplica al coste de la mercancía situada ya a bordo (free on board), aunque ahora, con la casi completa integración intermodal, se utiliza con más propiedad el término free carrier (FCA). Véase <www.incoterms-2010.com>.

${ }^{30}$ Esto ya fue advertido por el cónsul británico en Málaga, que en 1866 firmaba un informe sobre la potencialidad del distrito minero andaluz y la construcción de las nuevas líneas de ferrocarril. Sierra Morena, Sierra Nevada y Sierra de Gádor eran sus centros productivos de interés. Report of the Mineral Districts of Andalusia, 1866.
} 
Figura 3

Evolución de los índices de los tráficos ferroviario y portuario, y de la producción minera en Andalucía, 1870-1935

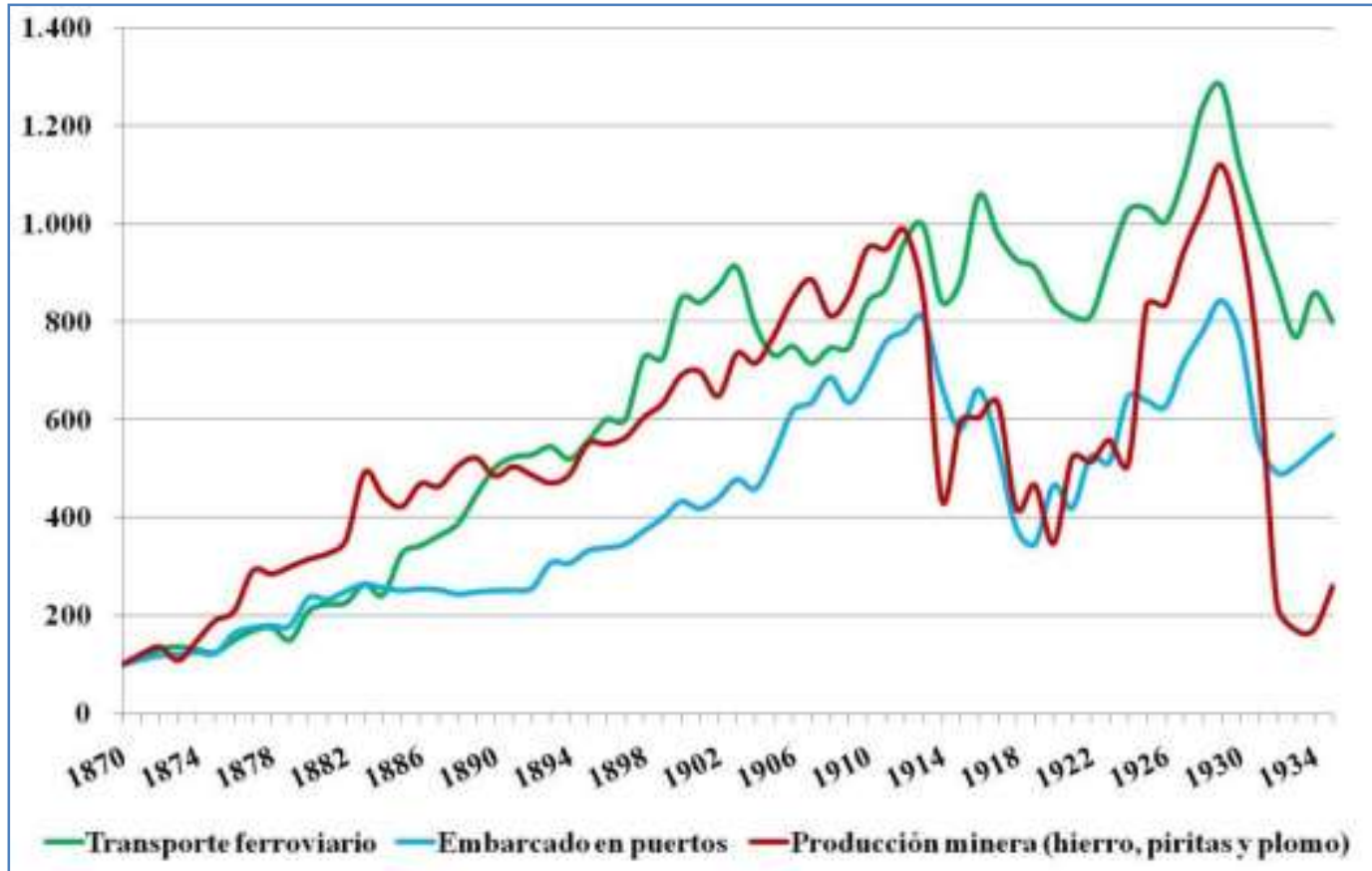

En miles de toneladas. $1870=100$

Fuente: elaboración propia a partir de Parejo, 1997, Ruiz, 2004 y Cuéllar, Jiménez Vega y García Raya (2008).

Los cables aéreos, la opción más económica pero de menor capacidad, se concentraron en la minería almeriense, estando justificados por la combinación de estas tres circunstancias: la fragosidad del terreno, una dotación de recursos explotables relativamente modestos, y la cercanía al litoral o a un ferrocarril de vía ancha. Cuando la distancia era mayor y la cubicación del criadero generaba la suficiente expectativa, algunas empresas afrontaron la construcción de un ferrocarril minero.

El ferrocarril cumplió una función primordial en el modelo de crecimiento basado en las exportaciones que se había implantado en las comarcas mineras de Andalucía. El tráfico de minerales, soportado por el ferrocarril en el cenit de la expansión minera, fue decisivo para la integración del territorio andaluz en las redes comerciales internacionales dominantes en la época. La minería contribuyó de manera decisiva en la incorporación de Andalucía al mapa del comercio mundial y en otorgarle un protagonismo destacado en el avance del proceso de globalización perceptible antes de la primera guerra mundial.

Sin embargo, más allá de su papel en la coyuntura expansiva de la minería andaluza, los trazados ferroviarios más vinculados a los flujos mineros han presentado a largo plazo evidentes desventajas logísticas que han ido marcando su obsolescencia y abandono. El impulso minero al ferrocarril aportaría, en suma, unas infraestructuras de transporte con una débil definición como red (dada su marcada unidireccionalidad con trazados volcados hacia el litoral) que desde el principio se manifestaría reacia a la articulación con el resto del sistema ferroviario. Así, la progresiva desactivación de la minería en la mayoría de las cuencas históricas, y el impacto de otras modalidades de transporte (camiones) que han demostrado mayor versatilidad, han ido condenando al abandono a buena parte de los activos ferroviarios puestos en pie durante la expansión minera. 
Figura 4

Ferrocarriles mineros y cables aéreos en Andalucía en torno a 1910

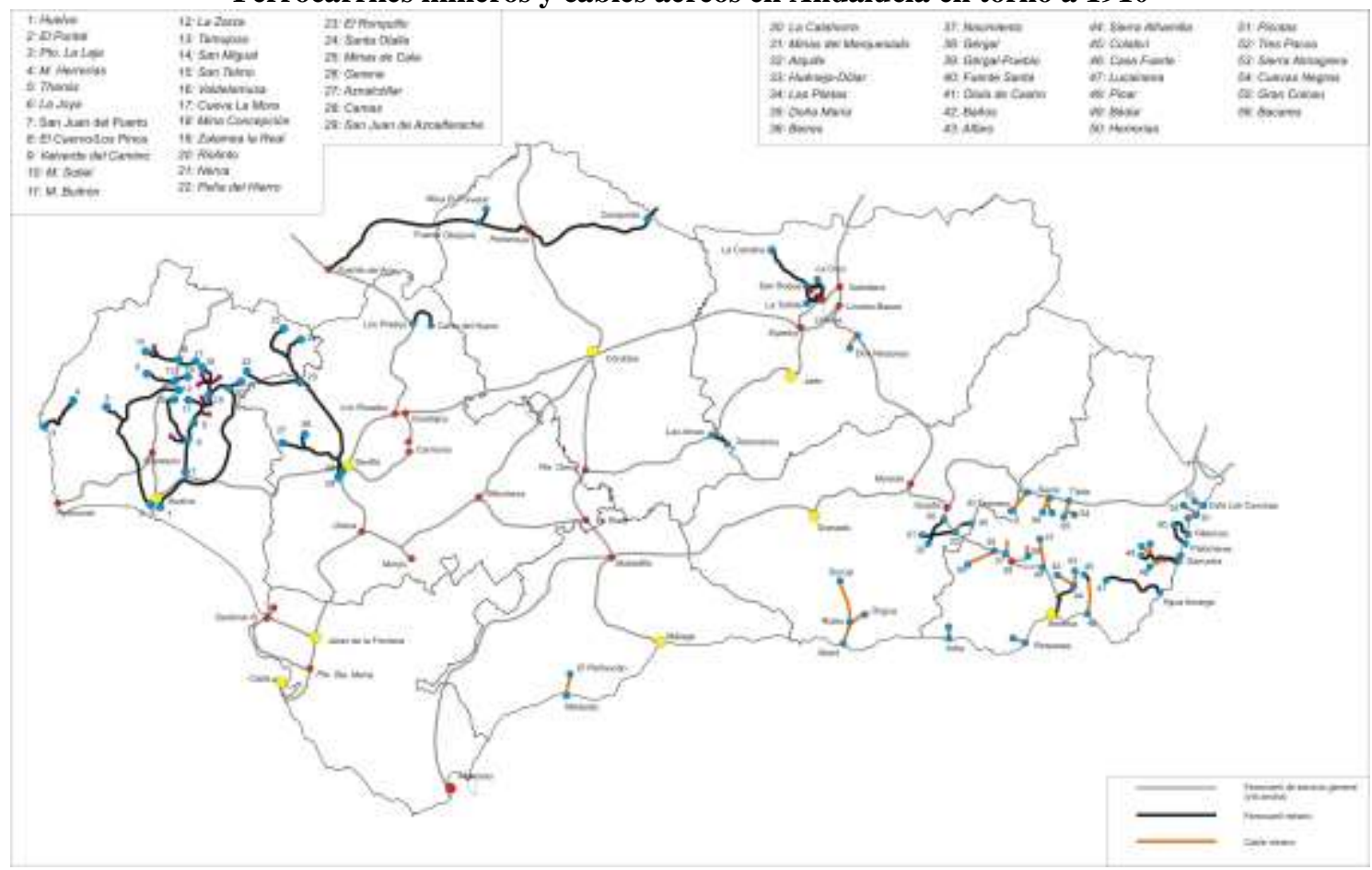

Fuente: Sánchez Picón, 2008, p 577.

Los tráficos mineros incorporaban como características propia, aparte de su bajo valor unitario, una demanda no condicionada por la estacionalidad, como sí ocurría con buena parte de los tráficos agrarios. La demanda de las industrias europeas fue relativamente regular y estable en el largo plazo y las sociedades mineras integradas verticalmente con algunos de sus clientes preferentes, se encontraban ante la disyuntiva de internalizar o externalizar el transporte hasta el punto de embarque. Las más importantes empresas (Riotinto, Peñarroya y Buitrón), pero también otras de menor entidad (Minas de Cala, Chávarri, etc.) optaron por la jerarquía y la coordinación, e integraron las infraestructuras de transporte dentro de su capital fijo (ferrocarriles mineros, embarcaderos), sujetas, en la mayoría de los casos, a las necesidades de la movilidad interna de productos, personas y materiales. Otras, como las sociedades de capital británico y francés de la cuenca férrica del Marquesado (Granada) o de los Filabres (Almería) tuvieron que recurrir a la compra del servicio del transporte a una empresa ferroviaria, incapaces de afrontar la costosa construcción de una red propia hasta los puertos de Almería o Águilas (Murcia). En el puerto almeriense acometerían, eso sí, fuertes inversiones para el levantamiento de cargaderos propios de mineral que fueran eficientes para la disminución de las estadías de la flota que acudía a recoger el mineral. Sin embargo, el recurso a la externalización y al mercado se mostró inseguro y llegaría a provocar, en la década de 1920, dada la insuficiente oferta ferroviaria, la paralización del distrito minero del Marquesado $^{31}$. La baja eficacia del mercado de transporte ferroviario para los graneles mineros, empujó, por lo general, a las compañías mineras a construir sus propios tendidos ferroviarios, sin aprovechar, en muchas ocasiones, la posibilidad de conectarse con la red general, así como sus propios dispositivos de embarque. Esta salida conllevaba un elevado riesgo de duplicidad (como ocurre en Huelva) y, por su propio carácter detraía a una parte significativa de la red ferroviaria de la oferta de servicios de transporte al conjunto de la economía andaluza.

\footnotetext{
${ }^{31}$ Sánchez Picón, 2008.
} 


\section{La distribución de la producción agraria}

El transporte de productos agrarios por ferrocarril y su incidencia en la unificación de los mercados nacionales ha sido de uno de los objetos de preferente discusión por parte de los investigadores. Un marco agrario dominante, como era el caso de Andalucía durante el siglo XIX y una buena parte del XX, inclina a pensar que los intereses ferroviarios tuvieron en cuenta a la producción agraria y al aprovechamiento de los flujos existentes en ese momento. Sin embargo, en las dos fases principales de construcción de los ferrocarriles andaluces tuvieron especial interés la conexión de las grandes ciudades béticas, en el primer impulso, y el desarrollo de ferrocarriles mineros en la Penibética y Huelva, durante el segundo impulso. Aun así, la significativa densidad de la red andaluza -en comparación con el conjunto nacional- supuso que una parte importante de los trazados se tendió a lo largo de las principales zonas agrarias andaluzas, tanto en el valle del Guadalquivir como en las campiñas de tránsito.

Un buen ejemplo es el caso del denominado "ferrocarril de aceite" construido por Andaluces en las últimas décadas del siglo XIX entre Puente Genil (línea de Córdoba a Málaga) y Linares para buscar un doble flujo minero-industrial de suministro de carbón de Belmez a la industria de Linares y de llevar hasta el puerto de Málaga la producción de plomo de esa zona, sin tener que transitar por líneas de MZA. Sin embargo, pocos años después de su finalización las minas de Belmez fueron vendidas y el mercado internacional de plomos se hundió por lo que la factoría linarense ya no era un polo de atracción estratégico para el tráfico. Esto supuso para la línea ferroviaria un cambio de referencia en los tráficos, ya que también atravesaba por las zonas agrarias de las campiñas giennense y cordobesa en las que se estaba produciendo una expansión del cultivo del olivar, que se consolidaría en la segunda mitad del siglo XX. Además, esta producción tenía una importante cuota exportadora (en torno al 25\%), aunque no había terminado aún de definir su uso al sólo alimentario ${ }^{32}$.

Tampoco son ajenas a los intereses agrarios otras líneas ferroviarias, como el caso de la de Sevilla a Jerez y Cádiz, que como es sabido tuvo su embrión en la exportación de los vinos jerezanos, o las líneas de Puerto de Santa María y Sanlúcar, con el mismo fin. Así como la línea transversal que enlazaba las líneas de Córdoba a Málaga con Sevilla a Cádiz, a través de Marchena, cuya comarca se consideraba productora de cereales. Incluso la línea de Bélmez fue objeto de un eventual tráfico de cereales extremeños y manchegos que entraban en Andalucía y que posteriormente pasaron a la línea de Mérida a Los Rosales, abierta al tráfico por MZA en 1885.

Como es sabido, la producción agraria presenta unos condicionantes de estacionalidad que no se dan en la actividad minera o industrial, a los que se suma la inestabilidad de las propias cosechas, agravada en los cultivos de carácter extensivo, todavía mayoritarios en Andalucía. Además, algunos de estos productos tenían, como hemos dicho, una vocación exportadora, por lo que los mercados internacionales influían también en los precios y en el volumen de la producción demandante de servicios de transporte. En conjunto, el volumen del tráfico agrario en Andalucía se correspondía con esa relevancia del sector primario, y tal como apuntó Tedde, el movimiento de productos agrarios por las líneas de Andaluces era netamente superior al resto de mercaderías ${ }^{33}$. Sin embargo, una mirada en conjunto con el resto de líneas

\footnotetext{
${ }^{32}$ Sobre el olivar andaluz, Zambrana, 1987, y Parejo y Zambrana, 1994.

${ }^{33}$ Tedde, 1980, p. 58-67.
} 
de vía ancha matiza esa apreciación y muestra, hasta el agotamiento del ciclo minero, una importancia compartida (cuadro 1).

\section{Cuadro 1}

Comparación entre los tráficos ferroviarios mineros y los agroindustriales en Andalucía, 1907-1935 En miles de toneladas

\begin{tabular}{l|ccc|ccc|}
\hline & \multicolumn{3}{|c|}{ Minerales exportación } & \multicolumn{3}{c|}{ Productos agrícolas y sus derivados } \\
& Media anual & Índice & \% sobre total & Media anual & Índice & \% sobre total \\
\hline $1907-1913$ & 1.239 & 100 & 37,7 & 1.065 & 100 & 32,4 \\
$1914-1920$ & 1.104 & 89 & 29,3 & 1.252 & 118 & 33,2 \\
$1921-1930$ & 1.080 & 87 & 24,9 & 1.716 & 161 & 39,6 \\
$1931-1935$ & 1.237 & 100 & 27,3 & 1.861 & 175 & 41,1 \\
\hline
\end{tabular}

Fuente: elaboración propia a partir de la información estadística por productos de las compañías ferroviarias de Andaluces, Sur, The Great Southern of Spain Railway (Lorca-Baza-Águilas) (GSSR) y Compañía de los Ferrocarriles de Zafra a Huelva (ZH).

Aun así, es significativo que el movimiento de productos agrarios mantuviera una tendencia creciente y terminara superando (incluso en la medición de tonelaje) al tráfico minero de las líneas generales. Como también era creciente la presencia de los productos agrarios andaluces en las partidas de los puertos de Sevilla y Málaga, estudiados por Esperanza Frax, que establecen una clara correlación con el transporte ferroviario ${ }^{34}$.

Los productos agrarios objeto de nuestro interés desarrollaron, además, una importante industria agroalimentaria cuyo análisis global realizó Antonio Parejo ${ }^{35}$. Además en los flujos de tráfico ferroviario quedaron recogidas con mayor o menor precisión estas partidas, lo que permite un análisis comparado aproximado entre la producción agroindustrial andaluza y su transporte por ferrocarril, que debe ser ampliado al movimiento por cabotaje y exterior ${ }^{36}$.

Como se puede constatar en la información estadística que se analiza a continuación, no resulta complicado establecer una relación entre la producción y el tráfico consecuente ferroviario, si bien cada producto tuvo un comportamiento diferente. Encontramos dos casos en los que la identificación entre la producción y el transporte es clara, el azúcar (figura 5) y el aceite de oliva (figura 6). En el primer caso, ya tuvimos ocasión de comparar esta relación al estudiar las líneas ferroviarias orientales ${ }^{37}$, donde ya apuntábamos la estrecha relación entre la dotación ferroviaria, la instalación de factorías azucareras y la expansión del cultivo remolachero por las vegas granadinas y béticas ${ }^{38}$. En Andaluces, en Sur o en MZA se

\footnotetext{
${ }^{34}$ Frax, 1987, p. 37-49, 63-77 y apéndice estadístico.

${ }^{35}$ Nos referimos a las agroindustrias harineras, oleícola, azucarera-remolachera y vinícola. Ver Parejo, 1997, p. 203-234.

${ }^{36}$ Los registros de las compañías ferroviarias distinguen los productos del siguiente modo:
}

\begin{tabular}{|c|c|c|c|}
\hline Andaluces & GSSR & Sur & $\overline{\mathbf{Z H}}$ \\
\hline Aceites & Aceites y vinos & Aceites vegetales & \\
\hline Orujos & & Orujos & \\
\hline Azúcar & Azúcar y melaza & Azúcar & \\
\hline Remolacha & Remolacha & Remolacha & \\
\hline Cereales & Cereales & Cereales & Cereales \\
\hline Harinas & Harinas & Harinas & Harinas \\
\hline Vinos y aguardientes & & Vinos y aguardientes & Vinos y aguardientes \\
\hline
\end{tabular}

\footnotetext{
${ }^{37}$ Cuéllar, 2003, p. 272-274.

${ }^{38}$ Hay que recordar que nos estamos refiriendo en todo momento a la expansión del cultivo de remolacha azucarera, que vendría en esos años a sustituir la importancia de la caña de azúcar, limitada climatológicamente a
} 
consideraban de gran interés estos tráficos para la diversificación de la actividad de transporte por ferrocarril. El ciclo comenzaba con la recolección del producto que era llevado en carros y camiones hasta las estaciones de embarque o bien hasta la propia factoría. Desde las estaciones de embarque se llevaba por ferrocarril la remolacha hasta la fábrica, y una vez procesada resultaban dos manufacturas, el azúcar y la melaza, que llegaban a los mercados nuevamente por ferrocarril, cuando se trataba de transportes a media o larga distancia, o por carretera para los trasiegos más cortos. Además, por ferrocarril llegaban también habitualmente el carbón y otros productos de mantenimiento de la planta industrial, por lo que es comprensible que la compañía de Andaluces registrara con detalle la gran concentración de fábricas azucareras en Granada, a lo largo de la línea de Bobadilla y con conexiones a la floreciente red suburbana ferroviaria de esta ciudad, que también debió buena parte de su diseño al azúcar de la vega. Se ampliaron vías en la estación de Granada y se saludaba con gran orgullo la construcción de la número once en Antequera en $1890^{39}$.

Figura 5

Estimación de la evolución de la producción azucarera de remolacha en Andalucía con relación a los tráficos ferroviarios de esta mercancía, 1907-1935

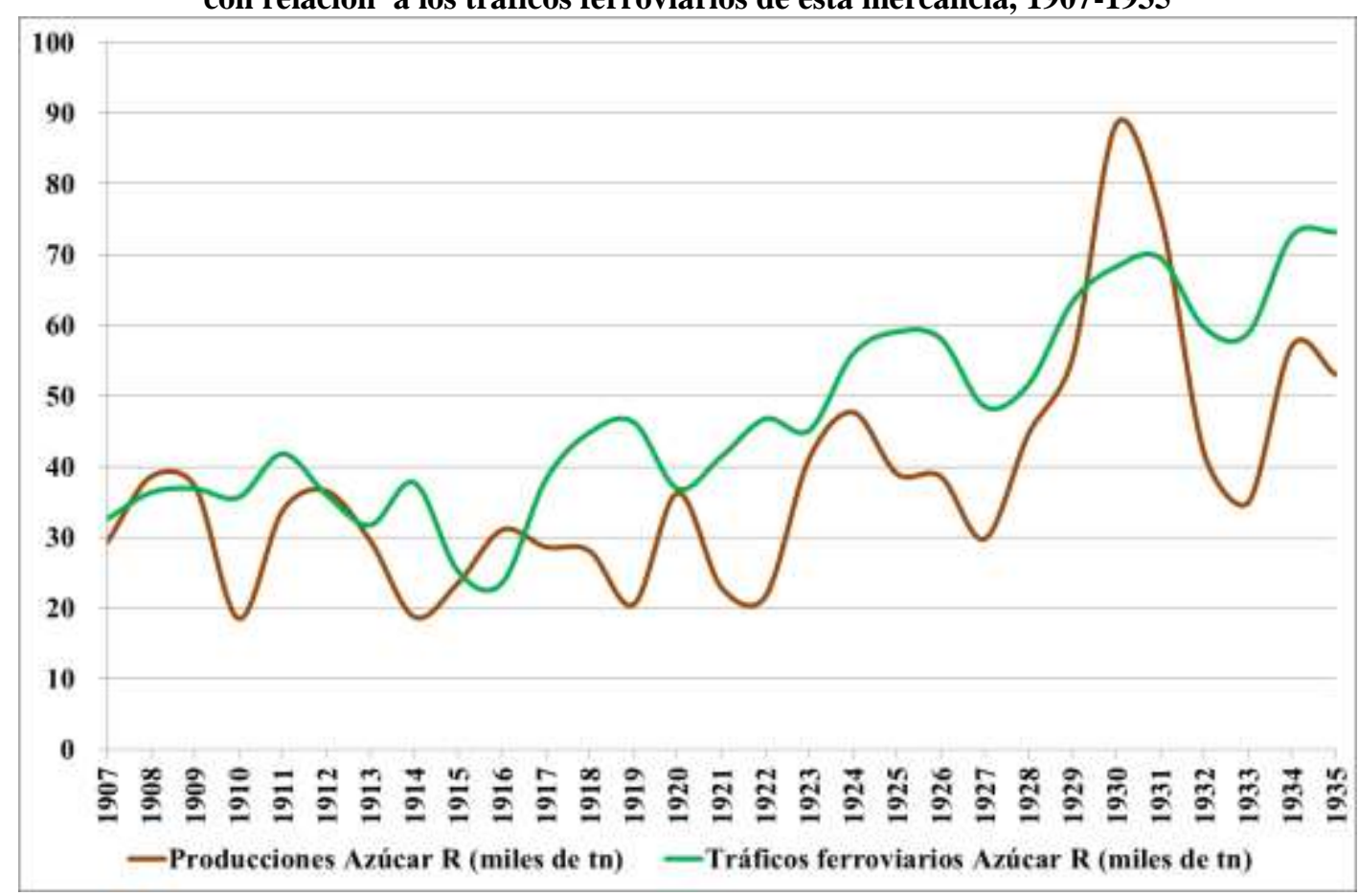

Fuente: elaboración propia a partir de Parejo, 1997 y Cuéllar, 2008a y b. Los datos de tráfico ferroviario se han obtenido a partir de la información estadística por productos de las compañías ferroviarias de Andaluces, Sur, GSSR y ZH.

Con respecto al aceite de oliva (figura 6) es visible la acusada fluctuación de unas cosechas a otras y su transmisión con un desfase anual (siempre transcurría un tiempo entre la recolección, el prensado y la comercialización) al transporte ferroviario, lo que causaba esas inestabilidades que tanto criticaban los dirigentes de Andaluces. El mayor crecimiento del tráfico ferroviario con respecto a la producción puede coincidir con el aumento que también se registra en los puertos andaluces de la producción aceitera destinada a cabotaje y, en menor medida, exportación, por lo que el canal habitual de llegada de esta producción desde el

las costas cálidas del sur andaluz y con escasa relación con líneas de ferrocarril. Sólo podemos contabilizar la línea de vía estrecha de Ferrocarriles Suburbanos de Málaga que llegó hasta Torre del Mar en 1908, cuando esta industria comenzó a declinar.

${ }^{39}$ Memorias de Andaluces, 1890, p. 31. 
interior de Andalucía sería a través de las líneas de ferrocarril. Morilla recogía la correlación producción y tráfico ferroviario, justificando que aquella condicionaba a éste ${ }^{40}$.

Figura 6

Estimación de la evolución de la producción aceitera en Andalucía con relación a los tráficos ferroviarios de esta mercancía, 1907-1935

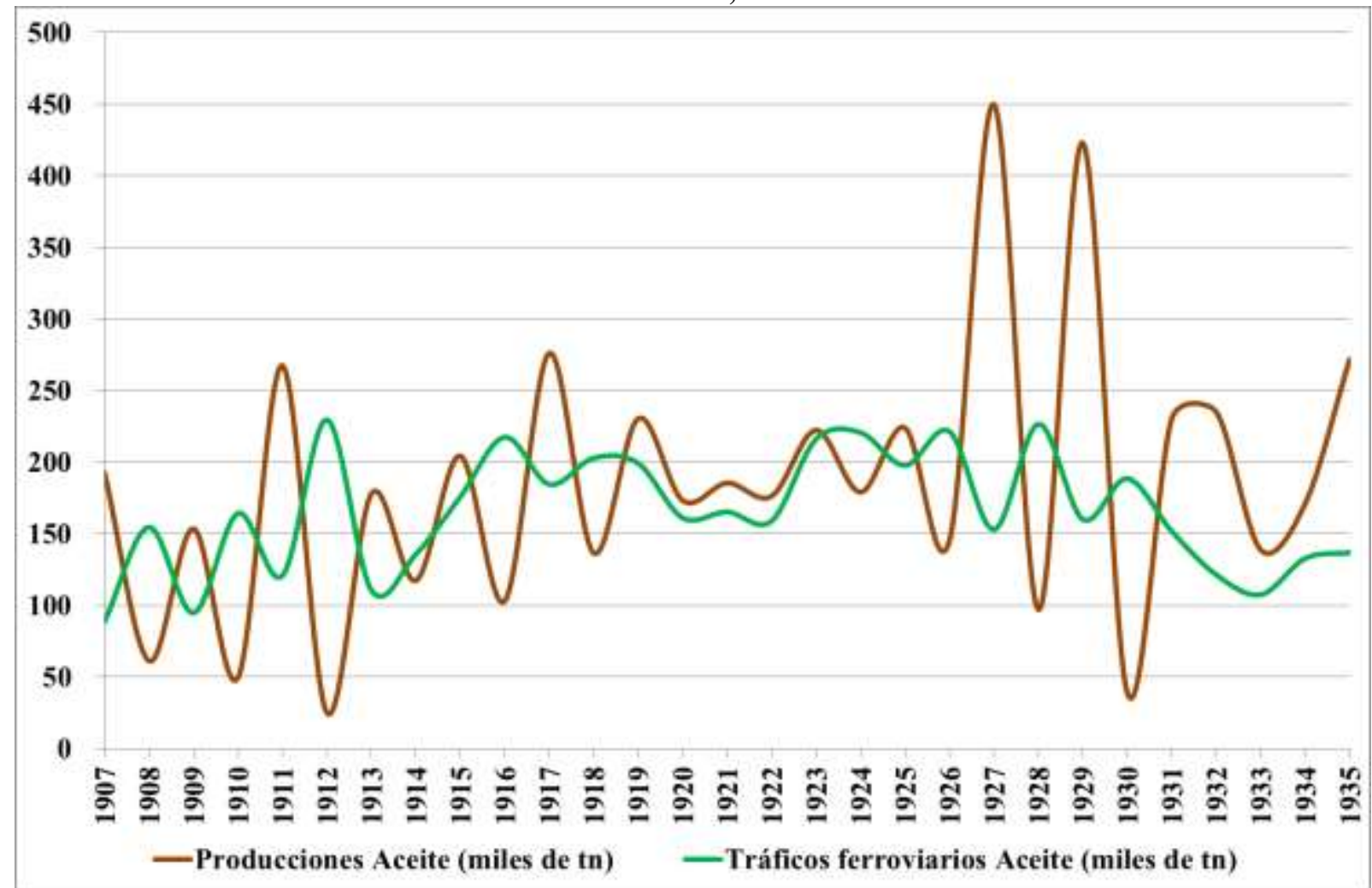

Fuente: elaboración propia a partir de Parejo, 1997 y Cuéllar, 2008a y b. Los datos de tráfico ferroviario se han obtenido a partir de la información estadística por productos de las compañías

Las divergencias de producción y tráfico las encontramos en dos casos bien distintos. Por un lado, la producción harinera (figura 7), que presenta pronto una disonancia con el tráfico de este producto, que crece de modo claro, mientras el estancamiento de la producción harinera andaluza es palpable y achacable, según Parejo, a la pérdida de competitividad de la industria harinera andaluza, incapaz de asumir el cambio tecnológico de la molienda clásica al sistema austrohúngaro de rodillos metálicos, mucho más eficiente ${ }^{41}$. Esto suponía la entrada de producción exterior, tanto harinera como de trigos peninsulares, que ya recogen con cierta asiduidad las memorias de las compañías ferroviarias, como extranjera por vía marítima, no por cabotaje $\mathrm{e}^{42}$, a través del tráfico internacional ${ }^{43}$.

En el lado inverso estaba el tráfico de vinos y aguardientes (figura 8): la producción está muy por encima de los tráficos. En este caso, la poderosa irrupción de la producción de destilados en Andalucía a partir de la Primera Guerra Mundial, distorsiona la información, ya que el tráfico ferroviario sí continúa atendiendo de modo habitual el movimiento de vinos, incluso con ligeros crecimientos en la década de 1920.

\footnotetext{
${ }^{40}$ Morilla, 2008, p. 545.

${ }^{41}$ Parejo, 1997, p. 207. Sobre la industria harinera española, Moreno Lázaro, 1997.

${ }^{42}$ Véase Frax, 1987, p. 69.

${ }^{43}$ Véanse los casos de Cádiz, Huelva, Sevilla o Almería. Ruiz, 2004, vol. 1.
} 
Figura 7

Estimación de la evolución de la producción harinera en Andalucía con relación a los tráficos ferroviarios de esta mercancía, 1907-1935

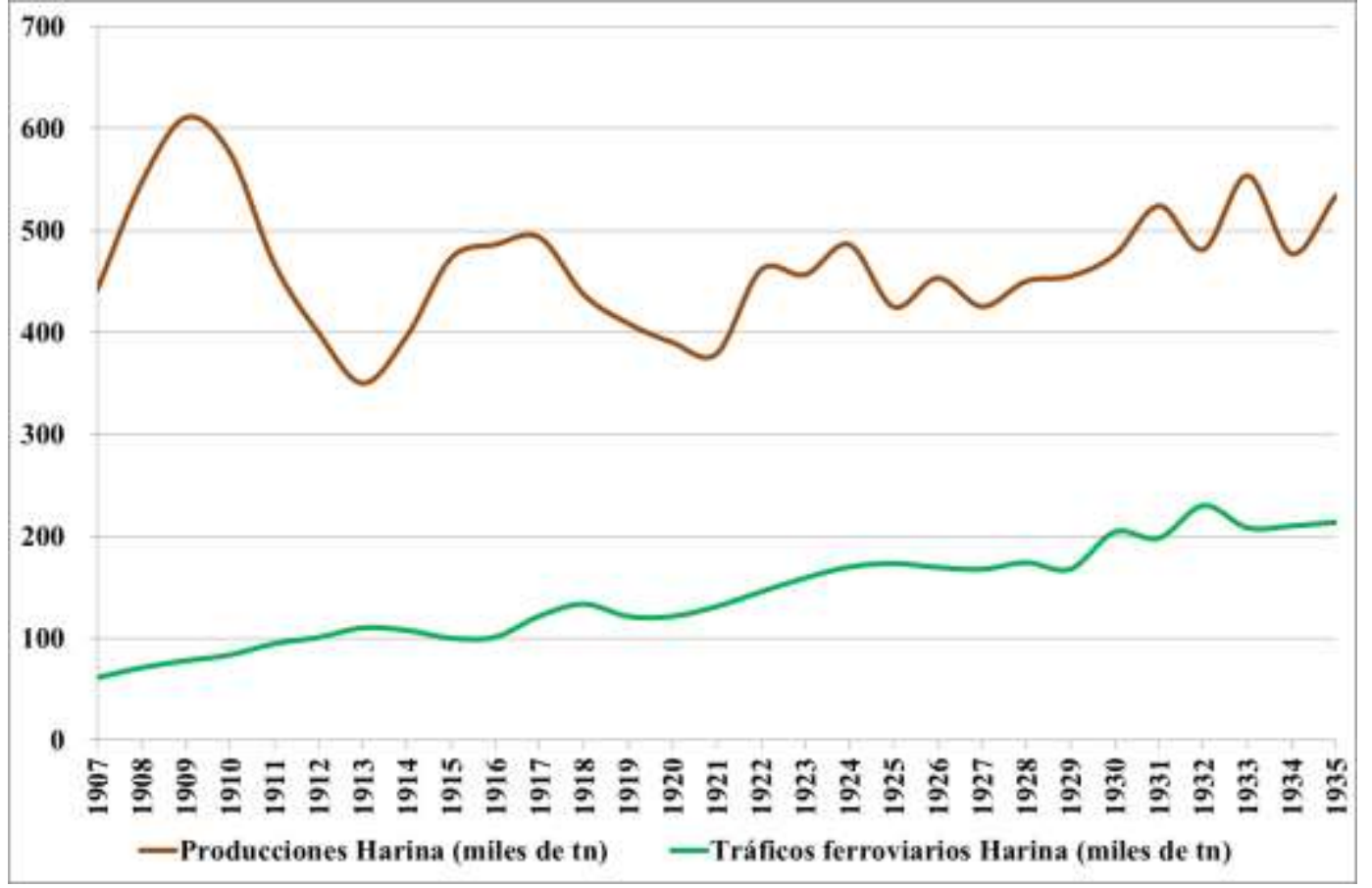

Fuente: elaboración propia a partir de Parejo, 1997 y Cuéllar, 2008a y b. Los datos del tráfico ferroviario se han obtenido a partir de la información estadística por productos de las compañías ferroviarias de Andaluces, Sur, GSSR y ZH.

Figura 8

Estimación de la evolución de la producción de vinos y brandy en Andalucía con relación a los tráficos ferroviarios de esta mercancía, 1907-1935

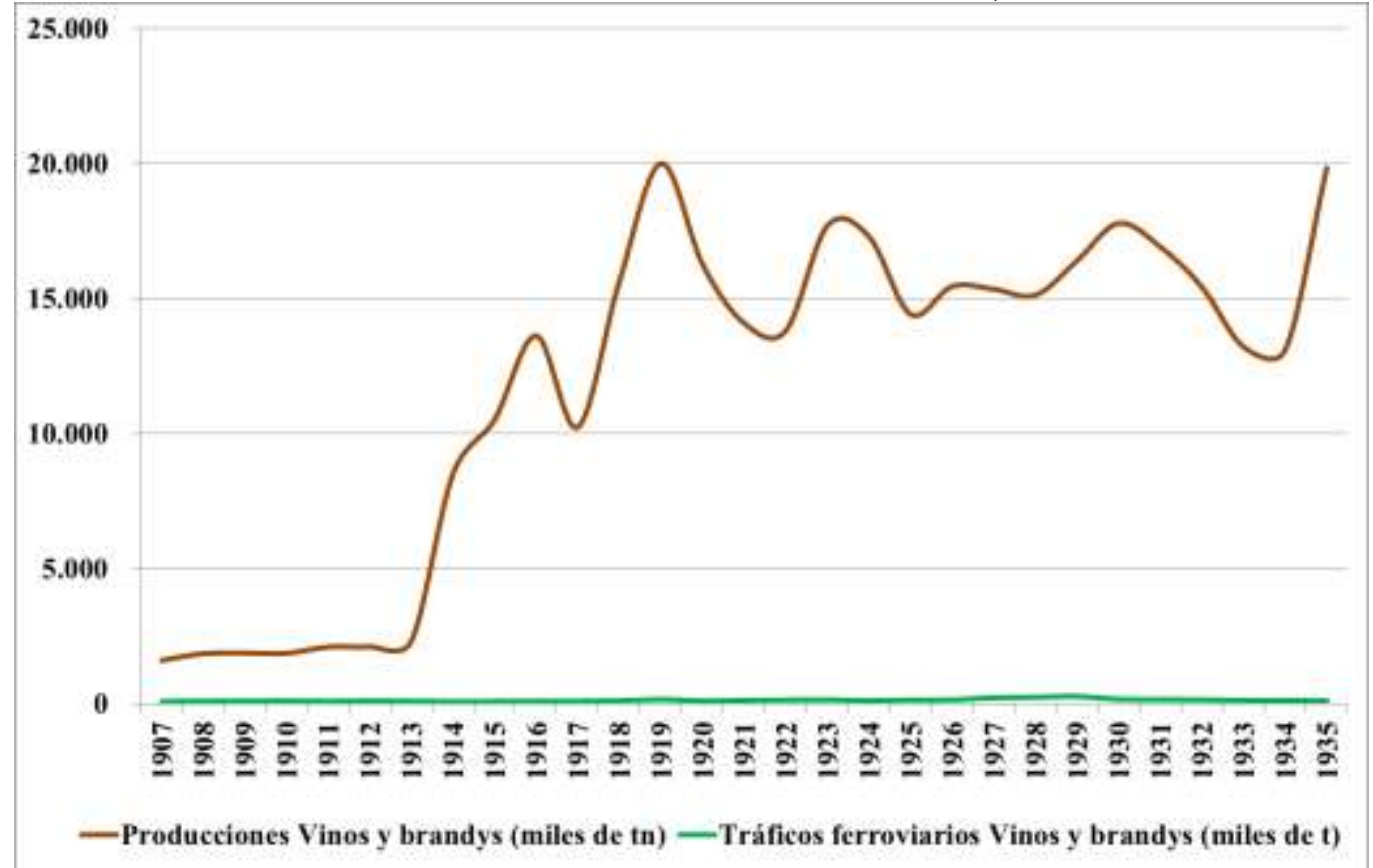

Fuente: elaboración propia a partir de Parejo, 1997 y Cuéllar, 2008a y b. Los datos de tráfico ferroviario se han obtenido a partir de la información estadística por productos de las compañías ferroviarias de Andaluces, Sur, GSSR y ZH. 
El incremento de la producción de brandy y cognac en la comarca jerezana será drenado por el tráfico por cabotaje, especialmente desde el Puerto de Santa María a Cádiz, y a la exportación desde este punto ${ }^{44}$. En este sentido, si, tal y como se ha señalado recientemente, el ferrocarril ganó la partida en un primer momento al tráfico fluvial en la consecución de los tráficos ferroviarios tras la llegada de este a mediados del siglo XIX, después las alternativas serían varias y, como hemos comentado anteriormente, y estos autores defienden, desde la comarca jerezana se buscó siempre reducir la dependencia de transporte con Cádiz, alentando el desarrollo de escenarios portuarios más cercanos, más capaces y con menos dificultades de acceso $^{45}$. Así ocurrió con la dársena de El Puerto de Santa María, que consiguió en 1908 su designación como puerto de interés general, y con el muelle de Bonanza, que había sido ansiosamente demandando por los tráficos ferroviarios de Andaluces.

Un indicador de modernización del sistema agrario es la constatación del uso de fertilizantes industriales como los abonos químicos. Andalucía incrementó su utilización a un ritmo ligeramente inferior a la media española y utilizó con preferencia los fosfatos sobre abonos nitrogenados o potásicos, lo que estaba relacionado con la implantación de agriculturas intensivas, de regadío, entre las que las necesidades de la remolacha azucarera fueron importantes $^{46}$. Los registros ferroviarios en las líneas andaluzas muestran una clara tendencia al aumento de este tipo de transporte, en casi todas sus líneas, pero en mayor medida, en las zonas de la Bética. Desde la aparición de datos desagregados en 1907 se da un crecimiento constante que llega hasta el inicio de la Primera Guerra Mundial, cuando el tráfico se ha multiplicado ya por tres. En ese momento hay una paralización y caída de estos tráficos, que vuelven a emerger con fuerza a partir de 1919, alcanzándose un máximo de esta mercancía en el tráfico ferroviario de 480 mil toneladas en 1930. La caída consiguiente de la década de 1930 tiene que ver con la propia crisis económica internacional y con el crecimiento de un competidor importante como es el transporte mecanizado por carretera.

\section{El transporte de pescado fresco}

Un último episodio de análisis se centra el trasiego de diario de pescado fresco y marisco desde los puertos andaluces hasta el interior peninsular. Estos transportes, de los que existe constancia ya con la puesta en explotación de las primeras líneas ferroviarias, se incrementaron notablemente durante el primer tercio del siglo $\mathrm{XX}$, facilitados por el crecimiento de las capturas, por la ampliación de los mercados y por las mejoras en el transporte, que posibilitaban la llegada de pescado fresco en condiciones óptimas de consumo a mercados del interior tan importantes como la propia capital del Estado ${ }^{47}$.

\footnotetext{
${ }^{44}$ La coincidencia de las cifras de salidas por cabotaje en el Puerto de Santa María con las entradas por este medio en Cádiz (Frax, 1981), y la correspondencia con las cifras aportadas por Ruiz, 2004, de exportación de vinos por Cádiz, corrobora esta cuestión.

${ }^{45}$ Pérez Serrano y Román Antequera, 2011, que plantean un oportuno debate sobre los intereses políticos y las deseadas intermodalidades en el transporte.

${ }^{46}$ Simpson, 1997, p. 158-165.

${ }^{47}$ Entre 550-650 km de distancia a los principales puertos andaluces, lo que suponía, al comenzar el siglo XX, un tiempo de viaje por ferrocarril de 20 horas (puertos de Andalucía Occidental, más alejados pero con mejor ferrocarril) y 30 horas (puertos de Andalucía Oriental, más cercanos pero con peor relación ferroviaria). Véase, sobre los tiempos de viaje por ferrocarril, Cabanes y González, 2009.
} 


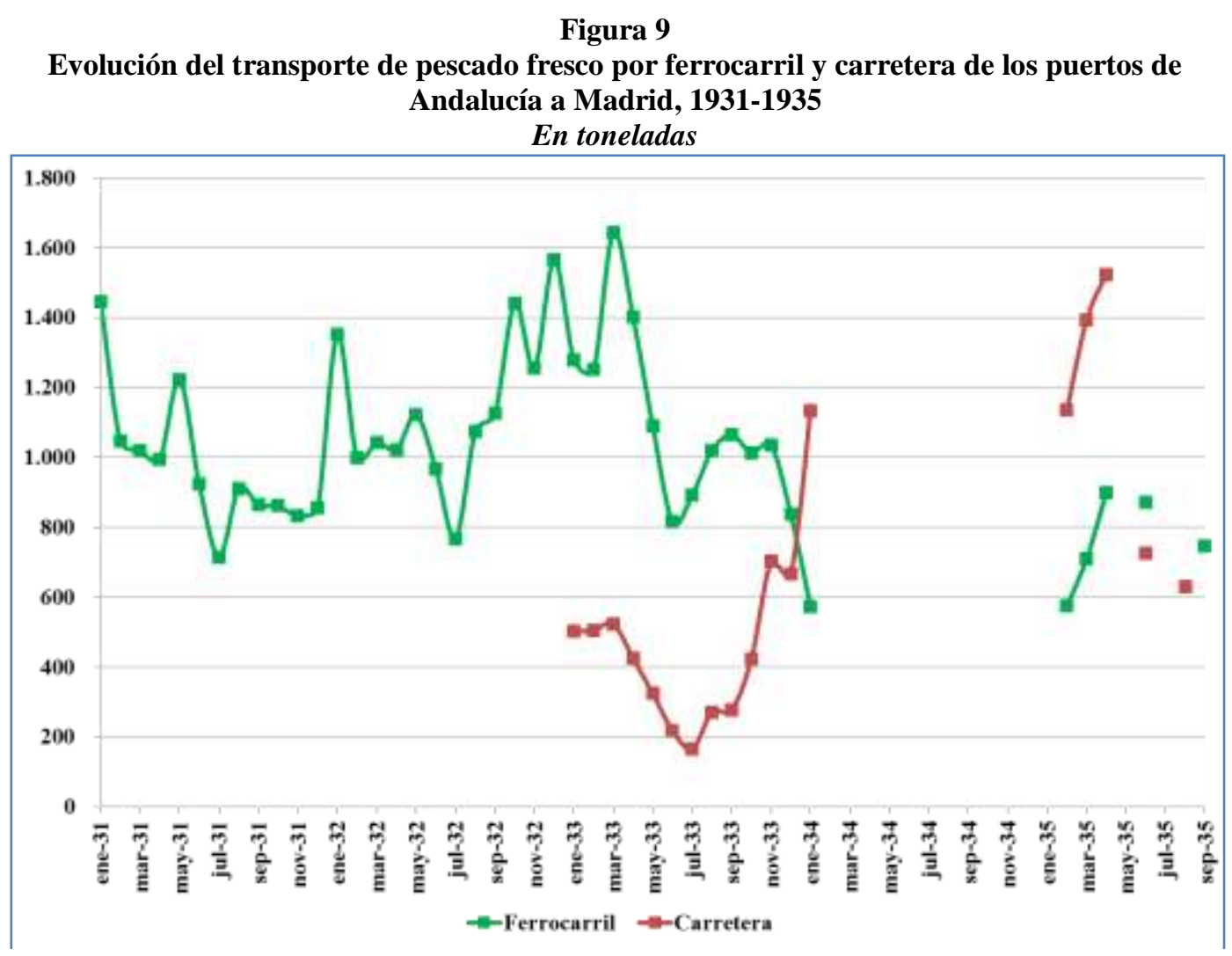

Fuente: elaboración propia a partir de Archivo Histórico Ferroviario (AHF), D-770-01, "Estadística de pescados llegados a Madrid por ferrocarril de los puertos del Sur", 1933-1935; AHF, D-770-02, "Estadística de pescados llegados a Madrid por carretera de los puertos del Sur", 1935.

Sin entrar en detalle sobre un tema todavía ausente de investigaciones en profundidad, sí nos interesa recoger a partir de los datos analizados (figura 8) como las compañías ferroviarias pasaron en un espacio breve de tiempo del monopolio absoluto del transporte de este producto a una rápida competencia que supuso la pérdida de una parte sustancial del mercado, a pesar de las mejoras introducidas mediante los vagones frigoríficos por parte de empresas especializadas como Transportes Frigoríficos o Ramón de Carranza S. A. La mayor flexibilidad del transporte mecanizado por carretera, tanto en los precios como en los horarios $^{48}$, estaría detrás de esa pérdida de capacidad del sector ferroviario. Las compañías observaron con preocupación esta situación $\mathrm{y}$, a pesar de la revisión tarifaria y otros incentivos, poco pudieron hacer salvo dar cuenta de los flujos de camiones que diariamente salían de los puertos andaluces con destino a Madrid, en competencia directa con las compañías ferroviarias $^{49}$.

\footnotetext{
${ }^{48}$ El pescado y marisco podía ser enviado por ferrocarril como mercancía de valor en los furgones de viajeros (cuando se trataba de cajas sueltas) pagando tarifa de Gran Velocidad, pero también podía formar parte de trenes de mercancías que llevaban mercancía urgente, también con tarifa elevada. Este era el caso del denominado "mensajero rápido", de MZA ( $\left.n^{\circ} 451\right)$, cuyos continuos retrasos en su llegada a Madrid preocuparon mucho a los responsables de la compañía (en septiembre de 1933 se anotan retrasos de hasta 3 horas). AHF, D-770-01, nota suelta.

${ }^{49}$ Los agentes comerciales de MZA enviaban datos continuamente. De esas notas e informes entresacamos una llamada de alarma, con una exhaustiva relación de camiones salidos de Cádiz y Barbate en noviembre y diciembre de 1932, del agente comercial de Sevilla, en enero de 1933, al jefe de servicio comercial de la compañía; éste anotó al margen la estrategia a seguir: “....esto ya va revistiendo importancia... Habrá que sacar
} 


\section{El sector industrial y generación de tráficos}

Un tercer espacio de intercambio sería el ámbito industrial, ejemplificado especialmente en las instalaciones industriales que se emplazaban en las proximidades de las redes de transporte. Éstas crecieron notablemente con la consolidación de las líneas ferroviarias y la ampliación de los puertos. Junto al ferrocarril se abrían apartaderos y vías de servicio exclusivas para la planta industrial que facilitaba el trasiego de mercancías. En los puertos cada vez fue más frecuente ver crecer polos de desarrollo industrial que buscaban un acceso más favorable a la cadena de distribución.

Figura 10

Tráficos de hierros y maquinaria por líneas ferroviarias andaluzas, 1907-1935

En miles de toneladas

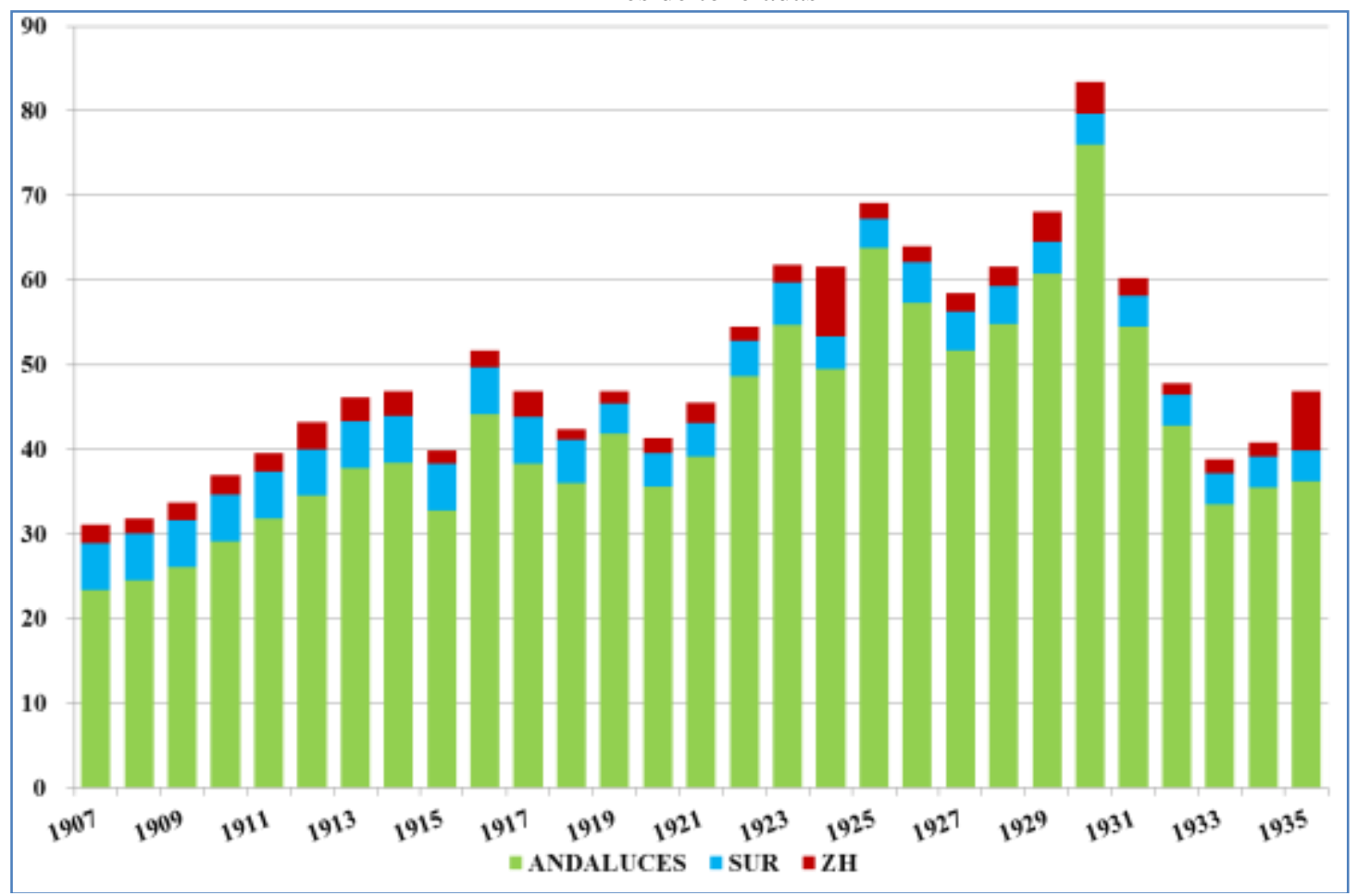

Fuente: elaboración propia a partir de la información estadística por productos de las compañías ferroviarias de Andaluces, Sur, GSSR y ZH.

La escasez de la industria siderúrgica en Andalucía, con la casi única referencia de la fundición Heredia, tuvo una breve reactivación en la coyuntura de la Primera Guerra Mundial, pero en ningún caso la producción tuvo repercusión en los tráficos ${ }^{50}$, sólo la llegada de mercancía nacional y, sobre todo, la importación de hierros y maquinaria a través de los puertos generó un incremento del movimiento de estas partidas. En todo caso los tráficos ferroviarios andaluces o los portuarios de hierros y maquinarias no aparecieron nunca entre los flujos más importantes (figura 10).

Más significativa fue la relación de la actividad ferroviaria y portuaria con la producción de las fundiciones de plomo que se distribuían por Almería, Jaén y Córdoba y que contaron,

copia de la presente y de la cifra que se averigüe por nosotros, escribiéndole a Andaluces y presentándole la solución para que nos diga si no hay manera de impedir la circulación de los camiones, lo que por su parte entiende que estaría dispuestos hacer para contrariar tan importante desvío". AHF, D-770-01, nota suelta.

${ }^{50}$ El primer cierre de 1907 de los altos hornos fue recogido con pesar en las Memorias de Andaluces, 1907, p. 6. Posteriormente esta misma fuente recoge el agrado por la reapertura, Memorias de Andaluces, 1918, p. 18. 
como ya hemos comentado al relatar la cuestión minera, con importantes redes de transporte ferroviario y conexión con puertos. Igual ocurría con la producción de las fundiciones de cobre onubenses que aprovecharon las líneas y enlaces que el tráfico de piritas había expandido en la zona. En el caso del plomo, la lucha por la consecución de los tráficos entre Andaluces y MZA constituye un referente fundamental de las estrategias que las compañías de transporte asumen para controlar el mercado ${ }^{51}$.

Como símbolo de la revolución industrial, correspondió durante mucho tiempo un papel estelar al tráfico de carbones por las líneas ferroviarias españoles y en los movimientos portuarios (figura 11). En los ferrocarriles, los ingresos que su transporte proporcionaba a las compañías, como en el caso de Andaluces podía rondar el $20 \%{ }^{52}$, si bien esta relación fue cayendo según se incorporaban nuevas mercancías y también nuevos combustibles, como los petróleos.

Figura 11

Tráficos de carbón por líneas ferroviarias andaluzas, 1907-1935 En miles de toneladas

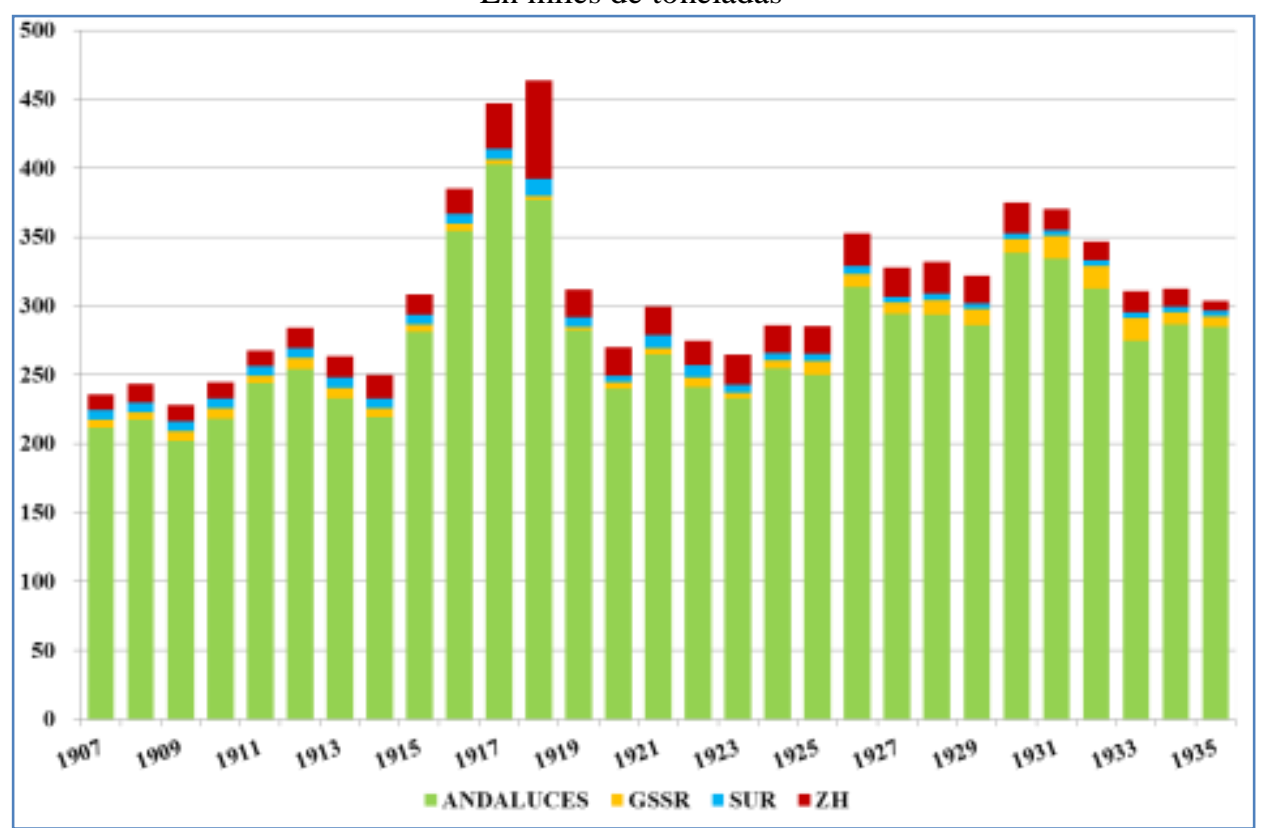

Fuente: elaboración propia a partir de datos estadísticos de las compañías.

El carbón era un elementos estratégico para la compañías ferroviarias y de transporte en general, que precisaban disponer de un stock suficiente para efectuar la tracción de los trenes con el menor coste, de ahí que pronto la compañías ferroviarias se aprovisionaran de yacimientos propios (Orbó y Ogassa para Norte, Villanueva del Río y Minas para MZA, y Belmez para Andaluces). Pero además, había una notable demanda de las industrias locales de carbón para las actividades de producción, a la vez que crecía la demanda urbana. Por lo tanto, la llegada de industrias suponía, no sólo un incremento de tráficos, propio de la industria en cuestión, sino también un aumento de la demanda de carbón. Así, en momentos de fuerte demanda, el suministro de carbón por parte de las compañías a las empresas instaladas en la zona se encarecía notablemente, mientras las crisis y caídas de precios, provocaban un efecto inverso y el ferrocarril se veía obligado a ofrecer tarifas más

\footnotetext{
${ }^{51}$ Véase Tedde, 1980, p. 152.

${ }^{52}$ Los ingresos por tráfico de carbones en Andaluces pasaron del 25\% de los ingresos en 1894, al $13 \%$ en 1910 , al $9 \%$ en 1920 y al $8 \%$ en 1930.
} 
competitivas, sobre todo cuando crecía la oferta de transporte, bien por el tráfico por carretera o bien por la construcción de nuevas líneas ferroviarias ${ }^{53}$.

Hay que resaltar el incremento que se detecta en el tráfico de carbones durante la Primera Guerra Mundial, propiciado por el encarecimiento que habían sufrido los fletes de los carbones foráneos a causa al conflicto bélico. Esto provocó un aumento de la demanda nacional y de sus tráficos en los yacimientos andaluces de referencia, Belmez y Peñarroya, hecho que se vio potenciado también por el establecimiento de una cuota obligatoria de consumo de carbón nacional en las actividades industriales a partir de ese momento ${ }^{54}$.

Figura 12

Tráficos de materiales de la construcción por líneas ferroviarias andaluzas, 1907-1935 En miles de toneladas

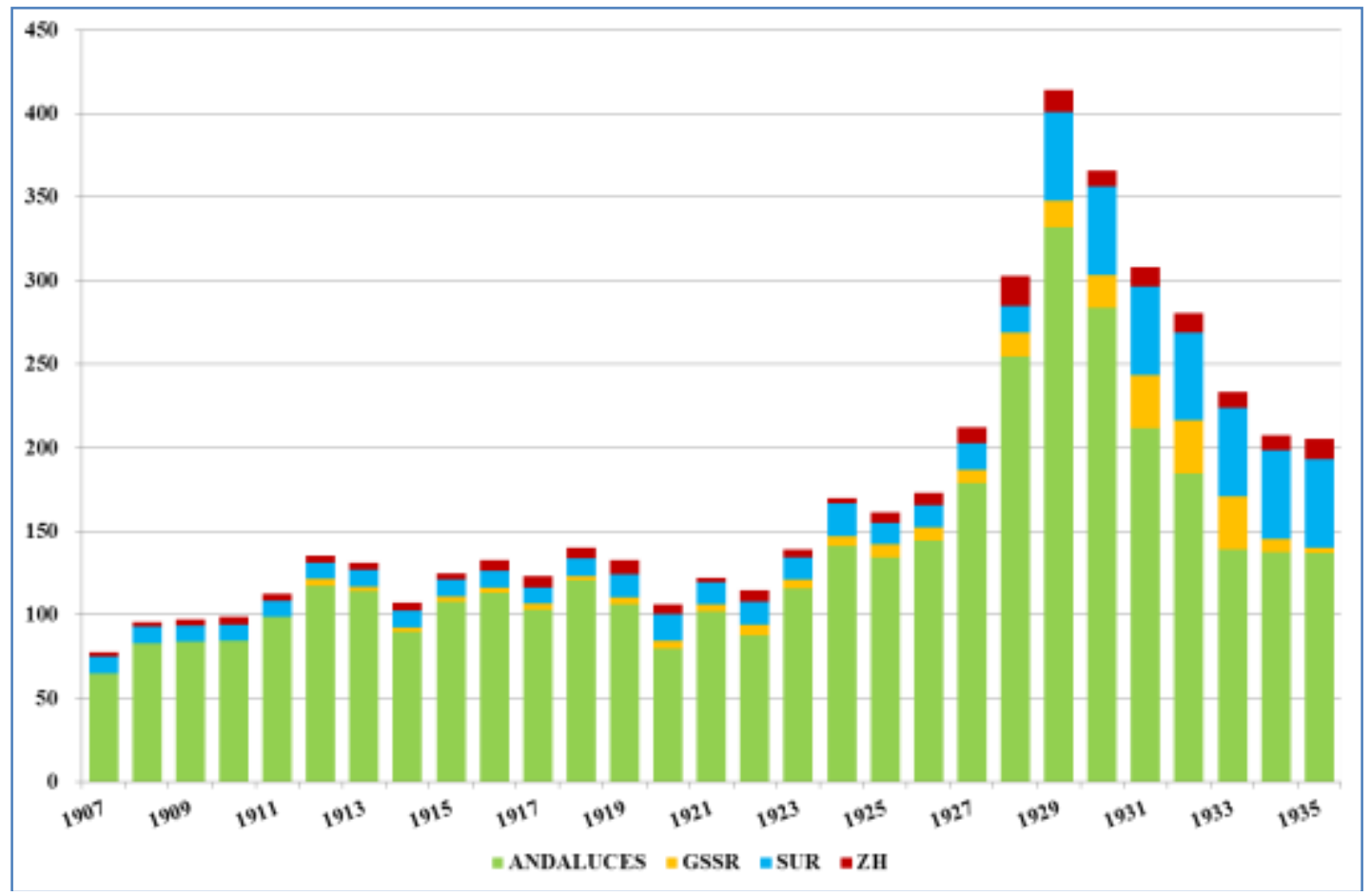

Fuente: elaboración propia a partir de datos estadísticos de las compañías.

En los puertos, la creación de los depósitos flotantes de carbón fue habitual y permitía suministrar rápidamente combustible a los barcos que realizaban en los respectivos puertos las labores de carga y descarga. Además, la diferente calidad y precio de los carbones nacionales y extranjeros hizo que el trasiego hullero fuera constante entre el litoral y el interior.

Dentro de la tendencia estable de muchos de los productos transportados por ferrocarril, destaca la clara evolución creciente de las mercancías clasificadas como materiales de construcción que desde la década de 1920 viven una década de crecimiento significativa (figura 12). El impulso del desarrollo urbanístico e inmobiliario perceptible en las grandes ciudades andaluzas, y en particular en Sevilla desde los años anteriores a la Exposición

\footnotetext{
${ }^{53}$ Así, la baja de precios del azúcar provocó también una caída del transporte por el descenso de la producción de las factorías ubicadas en la provincia de Granada, lo que haría también a las compañías ferroviarias reducir las tarifas del transporte del carbón, puesto que en el caso de la capital granadina, existía desde 1902 la competencia de la línea de Linares a Moreda y Granada. Memoria de Andaluces, 1901, p. 16, y 1902, p. 20.

${ }^{54}$ Coll y Sudrià, 1987.
} 
Iberoamericana de 1929, explican un comportamiento tan dinámico de este tipo de mercancías.

\section{Algunas relaciones intermodales}

Con las reservas conceptuales que ya señalábamos al comenzar este texto, el estudio de los primeros procesos de intermodalidad durante el primer tercio del siglo XX en Andalucía se centra prácticamente a las relaciones ferromarítimas ${ }^{55}$, debido, en primer lugar, al mayor volumen e importancia de aquéllas, en segundo lugar a las dificultades de acceso a las fuentes de tráfico caminero, y por último, también hay que señalar la inexistencia en Andalucía de otra relación propia de la etapa en otros puntos de Europa, y también de España, como eran los canales navegables. Además, dada la importancia de los flujos exportadores en el caso andaluz resultan visibles las tempranas estrategias de conexión física entre los ferrocarriles en construcción y los muelles portuarios.

Un primer recurso ha sido el análisis de la evolución de los tráficos ferroviarios y de los tráficos por cabotaje, para constatar cómo el ferrocarril atraía mucho más tráfico que el cabotaje. Esto resulta lógico, ya que la realización de las redes ferroviarias (y de carreteras) interiores hacía innecesarios muchos de los transportes marítimos interiores que se habían realizado hasta ese momento por las deficiencias del transporte terrestre. Como se puede ver en la figura 13, la distribución del uso modal entre 1870 y 1920 siguió una tendencia de clara hegemonía ferroviaria, que relegó rápidamente al cabotaje a una cuota de tráfico del 10-15\%.

Figura 13

Relación del tráfico por cabotaje con respecto al ferrocarril en España y Andalucía, 1870-1920

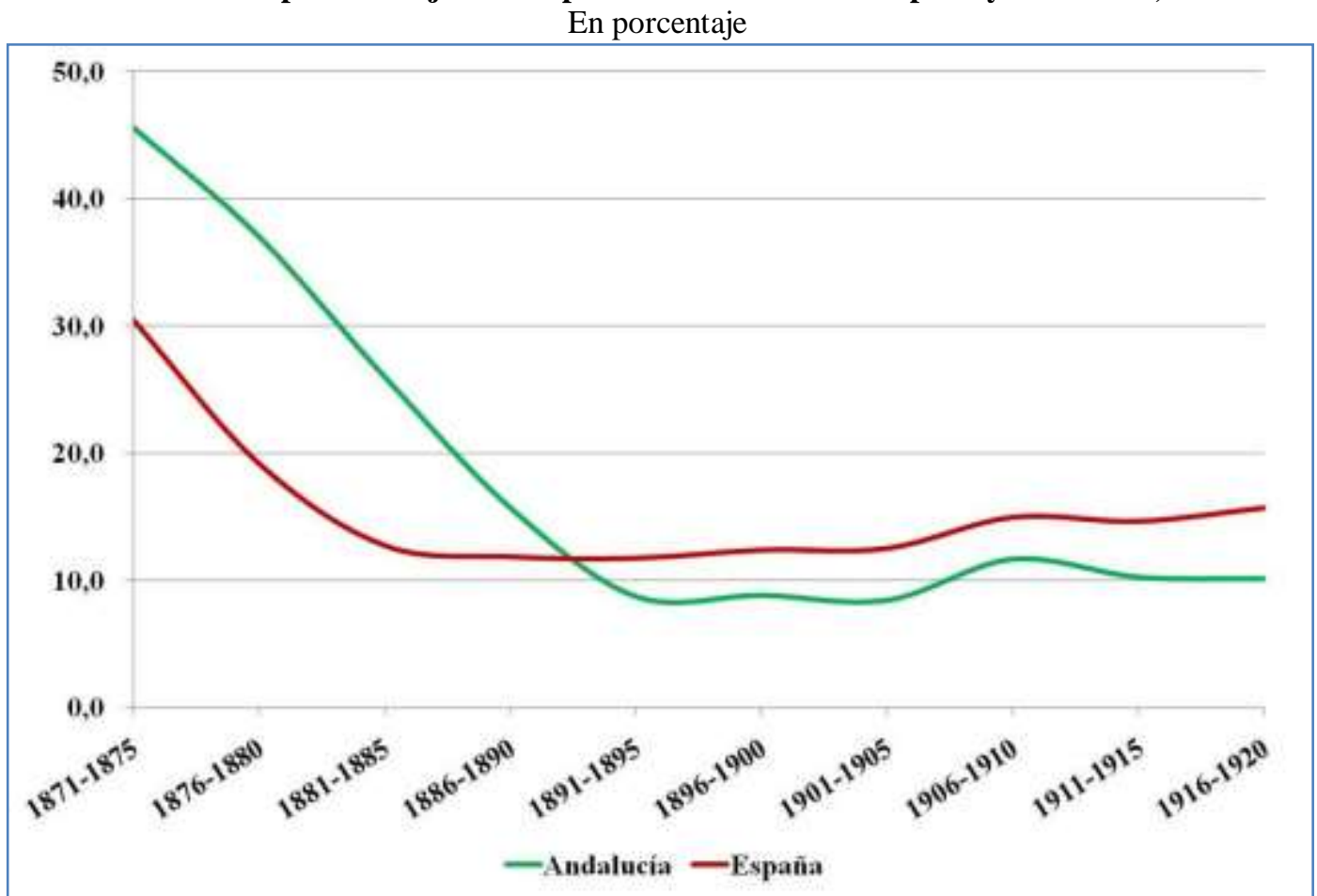

Fuente: elaboración propia a partir de Frax (1981) y Cuéllar, Jiménez Vega y García Raya (2008).

\footnotetext{
${ }^{55}$ En la actualidad las relaciones intermodales de mercancías se dividen en dos grandes grupos: intermodalidad terrestre, carretera-carretera o carretera-ferrocarril, e intermodalidad marítima, barco-carretera, barco-ferrocarril o barco-barco. Las relaciones con la aviación son todavía escasas. Véase Comisión de Transportes CICCP, 2005.
} 
Esto ocurrió de igual modo en el conjunto nacional y en Andalucía, si acaso se aprecia un cierto retardo en la transición modal en Andalucía, achacable al también retraso en la construcción de las líneas ferroviarias principales en Andalucía. Lo que sí es notorio es la estabilización del tráfico de cabotaje a partir de finales del siglo XIX, cuando éste encuentra una cuota de mercado propia que no admitía competencias.

El conocido incremento del tráfico ferroviario de mercancías en ese momento, supone también un crecimiento del tráfico de cabotaje en valores absolutos. Así, en el caso de los puertos andaluces, si la media de toneladas entradas y salidas en la década de 1881-1890 se situaba en 380 toneladas, entre 1891-1900 fue de 324 toneladas, en 1901-1910 subió a 473 toneladas, y en 1911-1920 llegó hasta las 565 toneladas $^{56}$.

De hecho, los datos registrados a partir de 1890, cuando las líneas ferroviarias andaluzas ya están construidas en su mayor parte (excepto en la zona más oriental) y también se ha llevado a cabo la construcción de una buena parte de la red viaria (nuevamente con el retraso de la zona más oriental), muestran una evolución paralela de los tráficos ferroviario y de cabotaje (figura 14), lo que es un indicador de cierta relación entre sí y de que ambos medios aprovecharon los crecimientos de la demanda de transporte, ya que también el cabotaje fue progresivamente modernizándose y aumentando, por tanto, la calidad de su oferta de transporte $^{57}$.

Lo que estaba ocurriendo en el transporte de cabotaje andaluz era similar a lo que pasaba en España: lento crecimiento o estancamiento en la segunda mitad del siglo XIX, inicio de una etapa de incremento mayor de los tráficos que se aceleró de forma brusca durante los años de la Primera Guerra Mundial, y caída bastante acentuada tras el final del conflicto bélico ${ }^{58}$.

Los puertos de Sevilla y Málaga fueron los que mostraron un comportamiento de crecimiento más definido. Buena parte de los tráficos que se registran en ese momento están relacionados con flujos que llegan desde el ferrocarril o que van a parar a él, o también es muy frecuente la redistribución de tráficos para el gran o pequeño cabotaje. Las salidas de aceite y plomo, dominantes en el puerto sevillano en estos años, son una buena muestra de ello, ya que arribarán a la rada sevillana a través de las líneas ferroviarias de MZA y Andaluces, y se redistribuirían después a otros puertos españoles. Las entradas registradas en el puerto de Sevilla se centraban en el dinamismo urbano y de la expansión industrial, con hierro y maderas como primeros rubros ${ }^{59}$.

Málaga presenta una doble cara, con un crecimiento sostenido de tráficos desde comienzos de siglo hasta los primeros años de la guerra mundial, y una caída muy brusca desde 1915. En el caso de las salidas, el puerto malagueño saca al circuito de cabotaje carbones y diversos productos agrarios, como aceite, azúcar, legumbres y vinos, que a su vez han llegado a través del ferrocarril y del cabotaje. Las entradas de algunos de estos productos agrarios, como cereales y azúcar, comparten protagonismo con una gran diversificación, entre la que sobresalen los hierros y los textiles ${ }^{60}$.

\footnotetext{
${ }^{56}$ Frax, 1981.

${ }^{57}$ Sobre el transporte de cabotaje en España, además de las referencias ya apuntadas de Frax, 1981 y 1987, véase para la estructura empresarial y su proceso de modernización, Valdaliso, 1997

${ }_{58}^{5}$ Frax, 1981, p. 31-36.

${ }^{59}$ Frax, 1987, p. 37-49.

${ }^{60}$ Frax, 1987, p. 63-77.
} 
En el caso concreto de los intercambios ferroportuarios hemos de señalar que su magnitud no era tan importante como en un principio se pudiera presumir, aunque en ningún caso es una cifra despreciable y su valoración final dependerá de su contraste con otros datos similares ${ }^{61}$.

Figura 14

Evolución de los tráficos ferroviarios y de cabotaje en Andalucía, 1890-1920

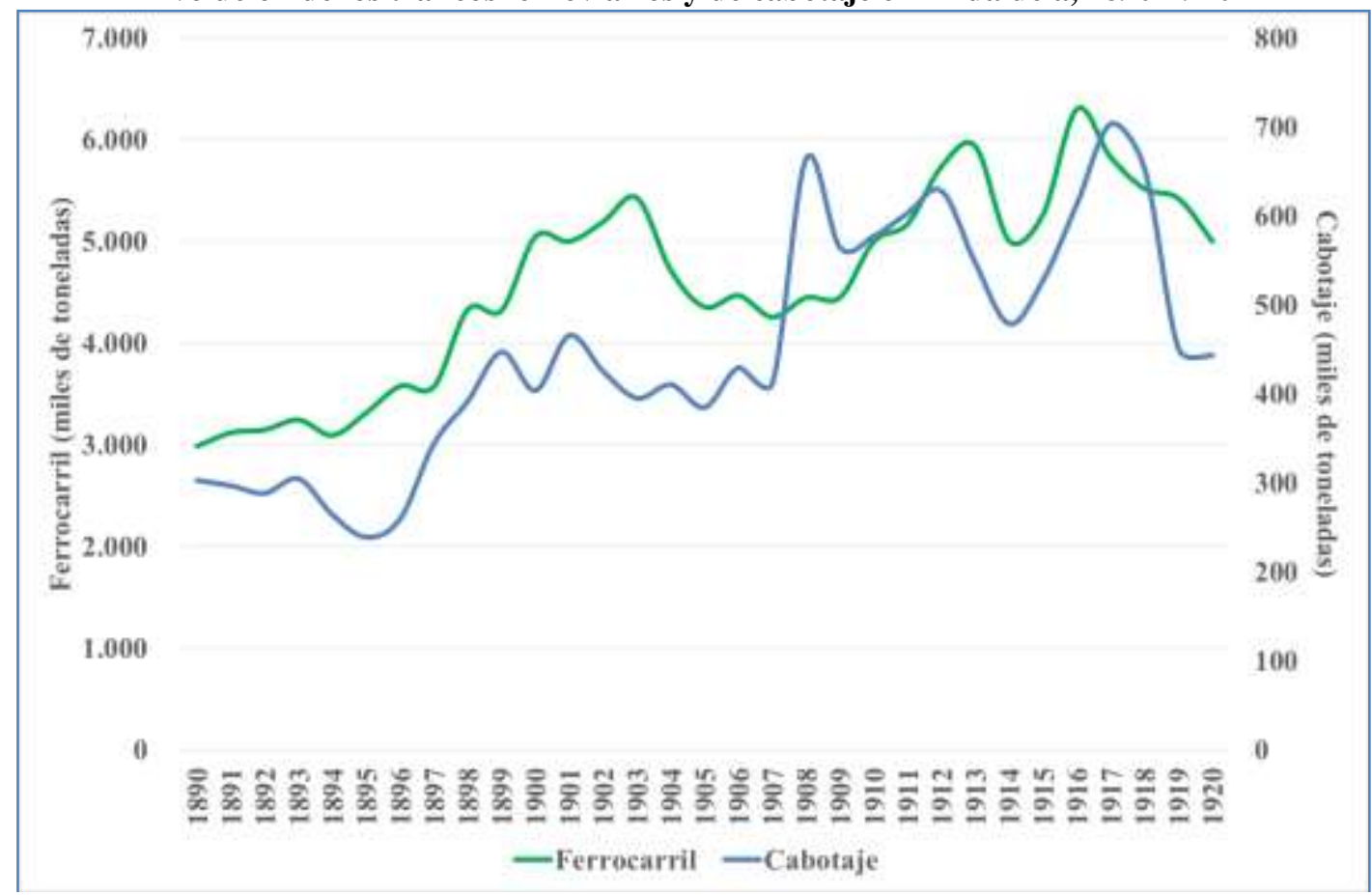

Fuente: elaboración propia a partir de Frax (1981) y Cuéllar, Jiménez Vega y García Raya (2008).

Según hemos recogido en el cuadro 2, este movimiento ferroportuario suponía entre el 5-7\% de todo el movimiento de mercancías que tenía la compañía ANDALUCES en todas sus líneas, mientras que para el conjunto del tráfico que se registraba en los puertos con los que tenía conexión esta compañía ferroviaria (es decir, todos, menos Huelva) la proporción se elevaba al 7-8\% del tráfico total.

Consideramos que estos datos pueden estar sesgados a la baja con respecto a la proporción real que tenían estos tráficos intermodales. Por un lado, el periodo para el que registramos datos es ya un periodo de retroceso del tráfico en Andalucía, y en algunos casos concretos, como hemos visto, muy significativo como los minerales de hierro que se embarcaban en el puerto de Almería. Por otro lado, la falta de información sobre los puertos de MZA también creemos que aminora los resultados ya que los tráficos mineros onubenses y los tráficos en Sevilla incidirían positivamente sobre la proporción de estos tráficos.

\footnotetext{
${ }^{61}$ En la actualidad, según datos de 2005, el tráfico ferroviario en España sobre los puertos supone el $2 \%$ de todo el tráfico portuario y algo más del $12 \%$ de todo el tráfico ferroviario. La escasa cuota de transporte de mercancías que tiene el ferrocarril (3-4\%) y el gran crecimiento de los tráficos portuarios a partir de la década de 1970, explican esta desproporción. Aunque también hay que tener que existen puertos que sí tienen un tráfico ferroviario más relevante (Tarragona, Santander, Bilbao o Barcelona), pero en ningún caso en Andalucía. El puerto de Málaga intercambia por ferrocarril 550 mil t al año, Algeciras 200 mil, Huelva 175 mil, Sevilla 140 mil, Cádiz 20 mil, mientras el puerto de Almería tiene clausurada la conexión ferroportuaria desde la década de 1980. Datos tomados de Maganto, 2007.
} 


\section{Cuadro 2}

Volumen de intercambios entre líneas de ferrocarril de Andaluces y puertos de Andalucía, 1926-1935 Miles de toneladas y porcentaje sobre total de tráfico de ferrocarril y puertos en Andalucía

$$
\text { Expedidas Llegadas } \% \quad \%
$$

\begin{tabular}{ccccc} 
& $t n$ & $t n$ & ferrocarril & puerto \\
\hline $\mathbf{1 9 2 6}$ & 206 & 164 & 5,5 & 7,1 \\
$\mathbf{1 9 2 7}$ & 325 & 150 & 6,8 & 7,8 \\
$\mathbf{1 9 2 8}$ & 235 & 226 & 5,9 & 7,4 \\
$\mathbf{1 9 2 9}$ & 295 & 139 & 5,4 & 6,4 \\
$\mathbf{1 9 3 0}$ & 285 & 180 & 5,8 & 8,0 \\
$\mathbf{1 9 3 1}$ & 223 & 155 & 5,5 & 8,2 \\
$\mathbf{1 9 3 2}$ & 225 & 131 & 5,9 & 8,9 \\
$\mathbf{1 9 3 3}$ & 159 & 135 & 5,3 & 7,9 \\
$\mathbf{1 9 3 4}$ & 159 & 136 & 5,4 & 7,3 \\
$\mathbf{1 9 3 5}$ & 171 & 116 & 5,0 & 6,3 \\
\hline
\end{tabular}

Fuente: elaboración propia a partir de Datos Estadísticos de ANDALUCES, varios años, Ruiz, 2004, y Cuéllar, Jiménez Vega y García Raya, 2008.

\section{Figura 15}

Tráfico ferroportuario de algunos productos en la estación de Sevilla-puerto de MZA, 1877-1886 En toneladas

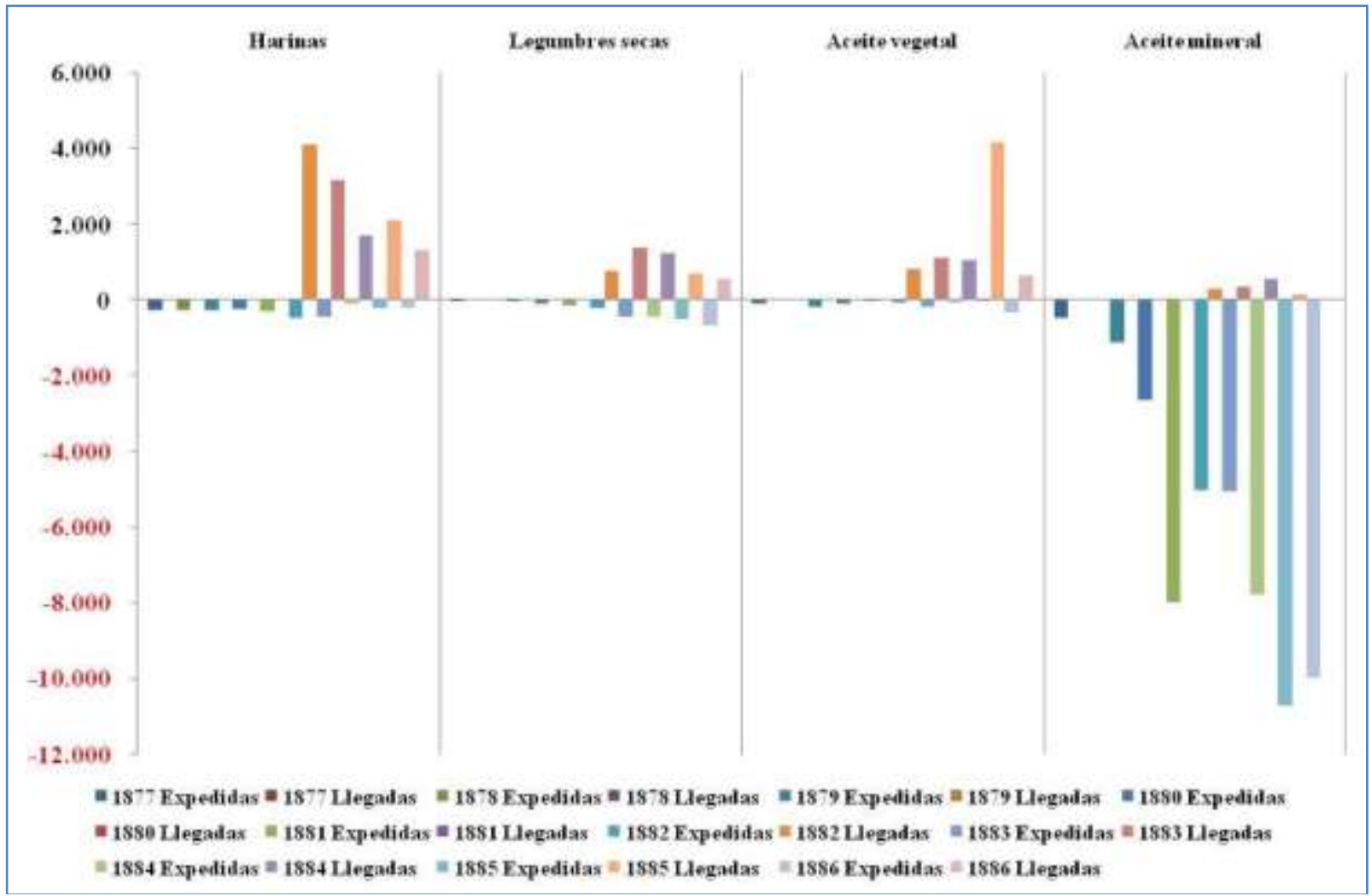

Fuente: elaboración propia a partir de Datos Estadísticos facilitados por las compañías de ferrocarriles a la comisión para el estudio de la crisis agraria y pecuaria (1888).

En todo caso, estamos hablando de cifras modestas y algo alejadas de los registros de los puertos españoles septentrionales donde, aunque no disponemos de cálculos similares, las estimaciones de Hernández Marco parecen sugerir esta diferencia, ya que los puertos sobre 
los que operaba la red de Norte, especialmente Barcelona (21\%, en la misma época), Bilbao (9\%, en 1910) y Pasajes (43\%, en 1910) tenían un mayor movimiento ferroportuario ${ }^{62}$.

En el caso concreto de los enlaces ferroviarios en los puertos andaluces, disponemos de alguna información discontinua que nos es útil para confirmar la utilización del flujo ferroportuario para la salida de productos primarios o de la agroindustria, harinas o aceites, y la entrada de productos relacionados con la industria como maquinaria, aceites y otros (figura $15)$.

Por otro lado, como era de esperar, la fortaleza de las relaciones ferroportuarias se manifestaba con mayor intensidad en los puertos que contaban con un amplio hinterland y con la aportación de líneas ferroviarias de carácter principal (figura 16). Éste es el caso de los puertos de Sevilla y Málaga, que sumaban los tráficos industriales, agrarios y de suministro urbano de una amplia zona de influencia, además de recibir una parte también significativa de tráficos de cabotaje de otros puertos cercanos. Además de estos dos puertos, la potencialidad de ciertos tráficos hacía crecer el flujo de mercancías, como los referidos casos de Almería y Huelva, relacionados con los tráficos mineros. Estos casos son fácilmente reconocibles por la desproporción entre los flujos de entrada y salida, ya que priman estos sobre aquellos.

Figura 16

Intercambio de mercancías entre el ferrocarril y los puertos en las estaciones marítimas de andaluces, 1926-1935

En toneladas

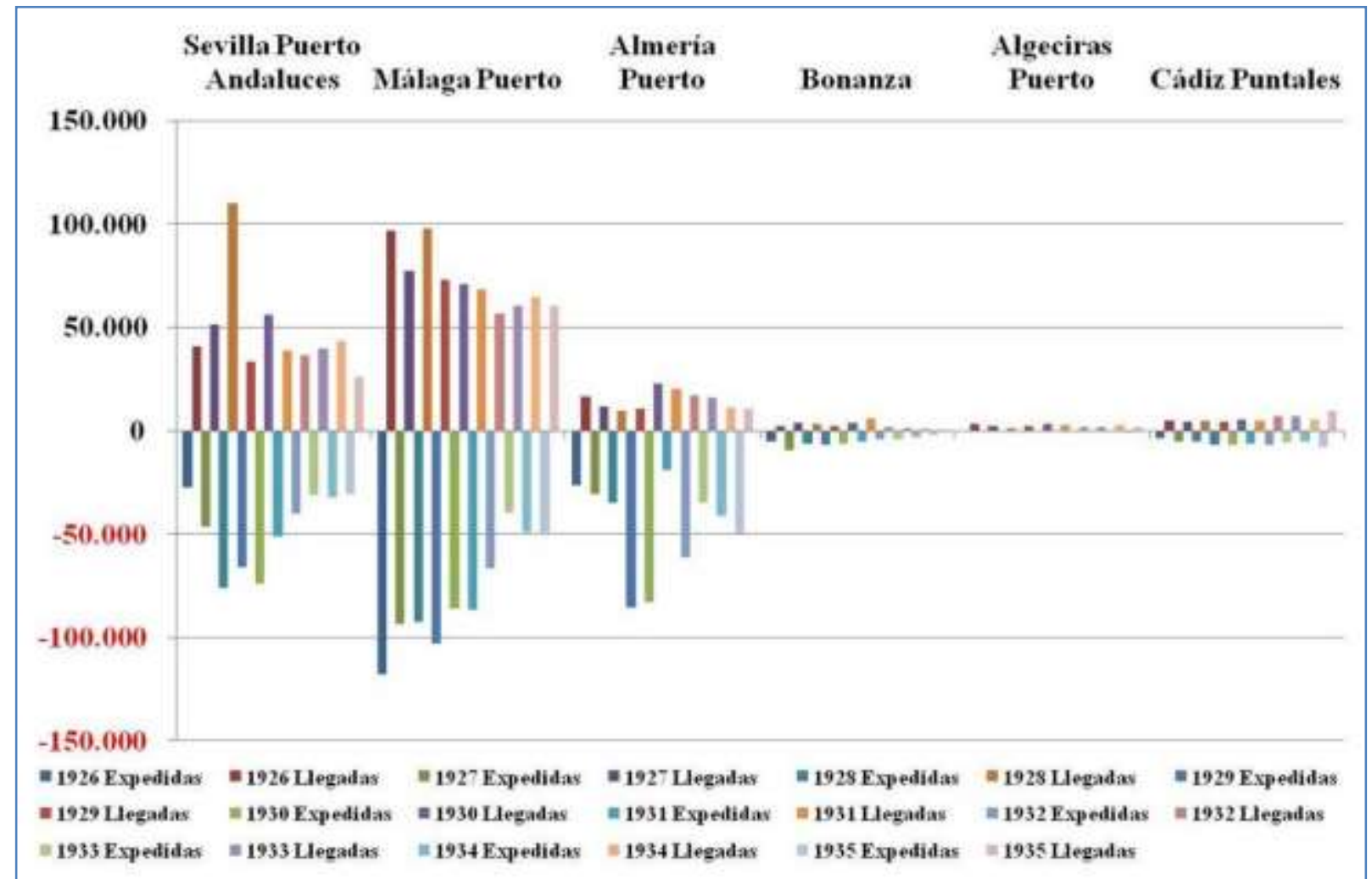

Fuente: Datos Estadísticos de Andaluces, varios años.

\footnotetext{
${ }^{62}$ Véase Hernández Marco, 1999, p. 607.
} 


\section{Conclusiones}

La red logística y de transporte en Andalucía se hizo más densa entre 1880 y 1930, alcanzando ya un grado de madurez suficiente a la altura de 1913, cuando se completaron los trazados ferroviarios, se amplió la oferta de carreteras y se culminaron las obras de construcción o mejora de la mayoría de las instalaciones portuarias. En un primer momento, durante la construcción de los ferrocarriles, las carreteras o los puertos, se produjo un aumento del uso de los factores, algunos de ellos de origen regional, con una destacada repercusión sobre la demanda de empleo y de una amplia gama de suministros procedentes de las comarcas circundantes. Desde este punto de vista, las cifras de inversión en estas infraestructuras a lo largo del periodo crecerían significativamente por debajo del promedio español. La inversión en ferrocarriles, carreteras y puertos, que en el periodo 1850-1880 se había situado entre el $20 \%$ y el $25 \%$ del total español, cayó entre siete y diez puntos, según el tipo de obra pública, a partir de la segunda década del siglo $\mathrm{XX}^{63}$.

Esta evolución de la red física, tal y como hemos estudiado en este texto, tuvo que atender una demanda claramente dual que se repartía entre la actividad mercantil tradicional de una base claramente agraria y la impetuosa tendencia exportadora de la mayor parte de la producción minera de la región, que se incrementó con algunas novedosas producciones agroindustriales.

Aunque el grado de integración económica en la región tropezó con dificultades debido a la extensión y la orografía, los flujos comerciales tanto dentro como fuera de ella aumentaron tras la construcción del ferrocarril y las mejoras en las infraestructuras portuarias. La disminución de los costes de transporte debió promover una especialización productiva a través del aprovechamiento de las ventajas comparativas, como predicen lo modelos de Ricardo y, para el comercio internacional, el de Heckscher-Ohlin ${ }^{64}$.

El ferrocarril fue el protagonista indudable, tierra adentro, de estos flujos, ya fuera para recoger los tráficos tradicionales como para posibilitar la explotación de recursos mineros mediante el diseño de líneas ad hoc. La navegación marítima, como hemos comprobado, acrecentó su relevancia a causa del crecimiento de los flujos exportadores, y generó unas interesantes relaciones pre-intermodales que buscaron la reducción de los costes de las rupturas de carga. El mejor ejemplo lo constituyeron las líneas y embarcaderos ferromineros que buscaban un transporte sin solución de continuidad desde los criaderos hasta las bodegas de los navíos. Tal y como se ha recogido en otros casos estudiados, las relaciones ferromarítimas fueron el primer escenario intermodal de éxito, por eficiencia y volúmenes, en el transporte contemporáneo.

También se apunta en estos años el arranque del transporte mecanizado por carretera (los camiones) y su capacidad de afrontar una competencia significativa a los transportes de la Primera Revolución Industrial. Estos, sin embargo, deben ser entendidos más como escenarios de disputa de tráficos que de coordinación o complementariedad.

\footnotetext{
${ }^{63}$ Sánchez Picón y Cuéllar, 2010b.

${ }^{64}$ Lizárraga, 2003, p. 53.
} 


\section{Bibliografía}

CHANDLER, Alfred D. La mano visible. La revolución en la gestión en la empresa norteamericana. Barcelona: Ediciones de Belloch, 2008.

CABANES, Ana y Raúl GONZÁLEZ. El tiempo del tren: las velocidades comerciales en las líneas españolas desde los orígenes hasta la actualidad. In $V$ Congreso de Historia Ferroviaria. Palma: Fundación de los Ferrocarriles Españoles, 2009.

COLL, Sebastián y Carles SUDRIÀ. El carbón en España, 1770-1961. Una historia económica. Madrid: Turner, 1987.

COMISIÓN DE TRANSPORTES DE CICCP. Libro Verde de Intermodalidad. Madrid: Colegio de Ingenieros de Caminos, Canales y Puertos, 2005.

CUÉLLAR, Domingo. Los transportes en el Sureste andaluz (1850-1950): economía, empresas y territorio. Madrid: Fundación de los Ferrocarriles Españoles, 2003.

CUÉLLAR, Domingo. El primer impulso ferroviario en Andalucía (1851-1880) y la Compañía de los Ferrocarriles Andaluces (1877-1936). In CUÉLLAR, Domingo y Andrés SÁNCHEZ PICÓN (Dir.), 150 años de ferrocarril en Andalucía: un balance, volumen 1, Sevilla: Junta de Andalucía, 2008a, p. 81-159.

CUÉLLAR, Domingo. El segundo impulso ferroviario en Andalucía (1880-1941): ampliación de líneas, capitales británicos e improntas mineras en el sureste y suroeste de la región. In CUÉLLAR, Domingo y Andrés SÁNCHEZ PICÓN (Dir.), 150 años de ferrocarril en Andalucía: un balance, volumen 1, Sevilla: Junta de Andalucía, 2008b, p. 161-239.

CUÉLlAR, Domingo; Miguel JIMÉNEZ VEGA; y Joaquín GARCÍA RAYA. Anexo estadístico: 150 años de ferrocarril en Andalucía. In CUÉLLAR, Domingo y Andrés SÁNCHEZ PICÓN (Dir.), 150 años de ferrocarril en Andalucía: un balance, volumen 1, Sevilla: Junta de Andalucía, 2008, p. 423-537.

CUÉLLAR, Domingo y Andrés SÁNCHEZ PICÓN. El impacto económico de un ferrocarril periférico: La Compañía de los Caminos de Hierro del Sur de España, 1889-1929. In MUÑOZ, Miguel, Jesús SANZ y Javier VIDAL (Eds.), Siglo y medio de ferrocarril en España, 1848-1998: Economía, Industria y Sociedad, Madrid: Fundación de los Ferrocarriles Españoles, 1999, p. 619-643.

CUÉLLAR, Domingo y Andrés SÁNCHEZ PICÓN (coord.). 150 años de ferrocarril en Andalucía: un balance. Sevilla: Junta de Andalucía, 2008.

DELAMARRE, Casimire. La province d'Almeria économique et sociale. Bulletin de la Societé de Gegraphie de Paris, 1867, t. XIII, juin, p. 529-547 y juillet, p. 51-67.

DATOS Estadísticos facilitados por las compañías de ferrocarriles a la comisión para el estudio de la crisis agraria y pecuaria. Madrid: Sucesores de Rivadeneyra, 1888. 
DEPARTAMENTO DE ASUNTOS ECONÓMICOS Y SOCIALES DE LAS NACIONES UNIDAS. Aplicación de la moderna tecnología del transporte al desarrollo de los recursos minerales en los países en desarrollo. Nueva York: Naciones Unidas, 1976.

FAIR, Marvin L. y Ernest W. WILLIAMS. Economics of transportation and logistics. Dallas: Bussines Publications, 1975.

FRAX, Esperanza. Puertos y comercio de cabotaje en España, 1857-1934. Madrid: Banco de España, 1981.

FRAX, Esperanza. El mercado interior y los principales puertos, 1857-1920. Madrid: Banco de España, 1987.

GARRUÉS IRURZUN, Josean y Juan Antonio RUBIO MONDÉJAR. La formación del espacio empresarial andaluz: 1857-1959. Scripta Nova. Revista Electrónica de Geografía y Ciencias Sociales. [En línea]. Barcelona: Universidad de Barcelona, 10 de junio de 2012, vol. XVI, no 404 . <http://www.ub.es/geocrit/sn/sn-404.htm>.

GÓMEZ MENDOZA, Antonio. Ferrocarril y mercado interior en España (1874-1913). 2 volúmenes. Madrid: Banco de España, 1984-1985.

HERNÁNDEZ MARCO, José Luis. El ferrocarril como ampliador de los espacios económicos portuarios: la compañía del Norte y algunos puertos septentrionales españoles entre 1878 y 1930. In MUÑOZ, Miguel, Jesús SANZ y Javier VIDAL (Eds.), Siglo y medio de ferrocarril en España, 1848-1998: Economía, Industria y Sociedad, Madrid: Fundación de los Ferrocarriles Españoles, 1999, p. 597-618.

HERNÁNDEZ MARCO, José Luis. Las primeras reacciones de las compañías ferroviarias al inicio de la competencia automovilística antes de la Guerra Civil. Revista de Historia Económica, 2002, año 20, primavera-verano, nº 2, p. 335-363.

LIZÁRRAGA MOLLINEDO, Carmen. La formación del espacio económico andaluz. Granada: Universidad de Granada, 2003.

MAGANTO, Julián. Oportunidades del ferrocarril en el sistema portuario español. In $L a$ intermodalidad portuaria, San Salvador de Bahía, Ministerio de Fomento, Interamerican Commitee on Ports, 2007.

MARNOT, Bruno. La genèse du concept d'intermodalité en France dans le transport des marchandises du début du XIXe siècle à 1934", TST, 2006, nº 10, p. 150-166.

MARTÍNEZ VARA, Tomás, y Francisco DE LOS COBOS ARTEAGA. Competencia y coordinación ferrocarril-carretera. Una visión desde la década de los treinta: Francisco Jiménez Ontiveros. In IV Congreso de Historia Ferroviaria, Málaga: Fundación de los Ferrocarriles Españoles, 2006.

MÉNDEZ, Ricardo. Geografía económica. La lógica espacial del capitalismo global. Barcelona: Ariel Geografía, 1997. 
MERLÍN, Pierre. Géographie, économie et planification des transports. Paris: Presses Universitaires de France, 1991.

MOKYR, Joel. La palanca de la riqueza. Creatividad tecnológica y progreso económico. Madrid: Alianza Universidad, 1993.

MOKYR, Joel. Los dones de Atenea. Madrid: Marcial Pons, 2008.

MORILLA, José. Contribución del ferrocarril a la especialización de la agricultura andaluza, 1860-1920. In CUÉLLAR, Domingo y Andrés SÁNCHEZ PICÓN (Dir.), 150 años de ferrocarril en Andalucía: un balance, volumen 2, Sevilla: Junta de Andalucía, 2008, p. 539551.

NADAL, Jordi. Los dos abortos de la Revolución Industrial en Andalucía. In DOMÍNGUEZ ORTIZ, Antonio (dir.), Historia de Andalucía, vol. VI. Barcelona: Planeta, 1984, P 399-433.

PAREJO, Antonio. La producción industrial de Andalucía (1830-1935). Sevilla: Instituto de Desarrollo Regional, 1997.

PAREJO, Antonio. Historia económica de Andalucía contemporánea. Madrid: Editorial Síntesis, 2009.

PAREJO, Antonio y Juan Francisco ZAMBRANA. La modernización de la industria del aceite de oliva en España en los siglos XIX y XX. In NADAL, Jordi y Jordi CATALÁN (Ed.), La cara oculta de la industrialización española. La modernización de los sectores no líderes (siglos XIX y XX). Barcelona: Editorial Ariel, 1994, p.13-42.

PÉREZ SERRANO, Julio, y Alejandro ROMÁN ANTEQUERA. La competencia por los transportes en la zona noroccidental de Cádiz: ¿vía fluvial, vía terrestre?, TST, 2011, n 20, p. 72-104.

REPORT of the Mineral Districts of Andalusia, which will be laid open by the completion of the Great Lines of Railway. Malaga: Consular Reports, 1866.

RUIZ, Elena María. Historia de la navegación comercial española. 2 volúmenes. Madrid: Ministerio de Fomento, 2004.

SÁNCHEZ PICÓN, Andrés. La integración de la economía almeriense en el mercado mundial (1778-1936). Almería: Instituto de Estudios Almerienses, 1992.

SÁNCHEZ PICÓN, Andrés (coord.). Industrialización y desarrollo económico en Andalucía. Un balance y nuevas aportaciones. Sevilla: Centro de Estudios Andaluces, 2013.

SÁNCHEZ PICÓN, Andrés. El ferrocarril y la expansión minera andaluza. In CUÉLLAR, Domingo y Andrés SÁNCHEZ PICÓN (Dir.), 150 años de ferrocarril en Andalucía: un balance, volumen 2, Sevilla: Junta de Andalucía, 2008, p. 555-593.

SÁNCHEZ PICÓN, Andrés y Domingo CUÉLLAR. El puerto de Almería (1805-2008). Una historia económica e institucional. Almería: Autoridad Portuaria de Almería, 2010a. 
SÁNCHEZ PICÓN, Andrés y Domingo CUÉLLAR. El despliegue logístico durante la Segunda Revolución Tecnológica. Una aproximación al caso andaluz (1875-1936). Antequera: Ponencia presentada a las Primeras Jornadas Internacionales de la Revista de Historia Industrial, 2010b.

SIMPSON, James. La agricultura española (1765-1965): la larga siesta. Madrid: Alianza Universidad, 1997.

TEDDE, Pedro. La Compañía de los Ferrocarriles Andaluces (1878-1920): una empresa de transporte en la España de la Restauración, Revista de Investigaciones Económicas, 1980, nº 12, mayo-agosto, p. 27-76.

THOMSON, J. M. Teoría económica del transporte. Madrid: Alianza Universidad, 1975.

VALDALISO, Jesús María. La navegación regular de cabotaje en España en los siglos XIX y $X X$. Guerras de fletes, Conferencias y Consorcios Navieros. Vitoria: Servicio Central de Publicaciones del Gobierno Vasco, 1997.

WEBER, Alfred. Theory of location of industries. Chicago: The Univesity of Chicago Press, 1929.

VAHRENKAMP, Richard. The Logistic Revolution. The Rise of Logistics in the Mass Consumption Society. Colonia: Josef Eul Verlag GmbH, 2012.

ZAMBRANA, Juan Francisco. Crisis y modernización del olivar. Madrid: MAPA, 1987.

(c) Copyright: Andrés Sánchez Picón, 2016.

(C) Copyright: Domingo Cuéllar, 2016

(C) Copyright Scripta Nova, 2016.

Ficha bibliográfica:

SÁNCHEZ PICON, Andrés; CUÉLLAR, Domingo. El soporte logístico de la especialización económica de Andalucía durante el primer tercio del siglo XX Scripta Nova. Revista Electrónica de Geografía y Ciencias Sociales. [En línea]. Barcelona: Universidad de Barcelona, 1 de diciembre de 2016, vol. XX, $\mathrm{n}^{\circ} 550$. <http://www.ub.es/geocrit/sn/sn-550.pdf>. ISSN: 1138-9788. 